\title{
Life safety risk-based requirements for concrete struc- tures in accidental situations caused by gas explosions
}

\author{
Ramon Hingorani, Dr. Civil Eng.*, Peter Tanner, Dr. Civil Eng.*, Carlos Zanuy, Dr. Civil \\ Eng.** \\ *Instituto de Ciencias de la Construcción Eduardo Torroja (IETcc-CSIC) \\ ** Universidad Politécnica de Madrid (UPM) \\ hingorani@ietcc.csic.es
}

\begin{abstract}
Accidental hazards are associated with large uncertainties regarding their occurrence probability, their effects on a structure and the possible consequences these effects might entail in case of failure. Consequently, decision-making related to safety accounting for such hazards is difficult and prone to be based on irrational grounds. Gas explosions in buildings are a good example therefore. Although dealt with in many codes, they are seldom accounted for in design of building structures. As a consequence, the associated risks are often ignored or sometimes consciously accepted. If this is a justified practice cannot be easily judged however, since under the implicit approach adopted in practice for assuring structural safety the risks are not quantified nor are the acceptable risk levels established.

On this background, the paper explores methods and tools for the practical application of explicit risk analysis in connection with the effects of gas explosions on RC structures. A procedure is established to determine structure-related risks to persons and applied to a representative set of structures designed according to current best practice. Target reliabilities for the design of key elements are deduced from the findings. Such target values facilitate rational decisions on both, the need and the appropriate choice of risk-reduction measures to counteract the effects of gas explosions in buildings.
\end{abstract}

\section{Keywords}

Accidental actions; Explosions; Concrete structures; Structural reliability; Risk analysis; Safety requirements

\section{Introduction}

In a technical context, risks are understood as a mathematical expectation of the consequences of an undesired event [55]. While not totally avoidable, risks can be analysed, assessed and, if required, reduced by appropriate measures. In daily structural design practice, the treatment of risks is generally implicit, i.e. they are not explicitly quantified and the question of their acceptability is judged on the base of prescriptive, codified rules. These rules are mainly based on experience and knowledge gained in the past. They approximately 
represent the state of best practice and provide reasonable grounds for the design of most structures under normal loading, operational and environmental conditions [22, 55].

In addition to the normal use conditions, structures might be exposed to abnormal or accidental actions, which are among the most common causes of structural failure [56]. Accidental actions may be characterized as low probability - high consequence hazards [15]. Hence, their occurrence during the envisaged design working-life of a structure is unlikely, but if it happens, and if not appropriately accounted for, the corresponding effects might entail significant consequences. Due to the high uncertainties involved, decision-making related to structural safety accounting for such actions is generally complex and prone to be based on irrational grounds. Explicit risk analysis might offer substantial advantages in this regard. In such an analysis, the specific characteristics inherent to accidental actions, such as their low occurrence probabilities, on one hand, and the potentially high failure consequences, on the other, can be judged in a rational manner in terms of risk $[16,56]$.

Among the possible accidental hazards in buildings, gas explosions account for a substantial number [58]. Despite the continuous modernization of gas installations and appliances, available statistics from different western countries show that the occurrence rate of such explosions still does not decrease in a significant way. Among the possible reasons is the fact that a certain proportion of the incidents is not attributable to technical shortcomings but to suicide attempts. Given their well-known hazard potential to structural safety, gas explosions are dealt with in many structural design codes. In Eurocode EN 1991-1-7 [20], for instance, they are demanded to be accounted for "in the design of all parts of the building (or other engineering works) where gas is burnt or regulated...". Specific guidance on practical implementation of associated design measures is provided e.g. in [57].

In spite of their consideration in codes and guidelines, gas explosions are only seldom accounted for in layout and design of building structures. Among possible reasons therefore, one might quote the reluctance to allocate funds to mitigate such kind of low-probability future events [15]. The question that rises is if "doing nothing" is a justified practice, or if certain risk reduction measures would be appropriate. Providing a knowledgeable answer to these questions calls for an explicit analysis and assessment of structure-related risks, what was addressed in the context of the $\mathrm{PhD}$ thesis of the first author [26]. The research presented in the present paper has been the subject of this thesis. Models for estimation of both the probabilities and the consequences to persons of a gas explosion-induced collapse in reinforced concrete (RC) building structures are presented. Following the general approach developed in previous studies $[50,51]$, these models are subsequently employed to determine the implicitly accepted life safety risks associated with such structures. Rational acceptance criteria for structural safety verifications of potentially explosion-exposed structural members are deduced from the findings. They could be employed in the framework of a performance-based reliability design or assessment. Moreover, they may serve as a basis for the calibration of semi-probabilistic models for applications in daily practice, following current developments for structure-related explosion hazards due to terrorist attacks $[2,48]$. 


\section{Methodology}

\subsection{Assumptions for the inference of acceptable risks}

Decision-making related to technical facilities in general, and structures in particular, unavoidably requires addressing life safety risks in order to assure that persons are safeguarded from undue threats to their life to the highest affordable level [23]. According to the Marginal Life Saving Cost (MLSC) principle established in the international standard on the reliability of structures [34], this level is closely related to the societal willingness to pay for saving one statistical individual and can be quantified by means of the Life Quality Index (LQI). However, the standard also states that "an activity which is found to be acceptable should be assessed in regard to the corresponding absolute level of life safety risk". Moreover, it specifies that the practical implementation of the MLSC principle by using the LQI might require the specification of "absolute values of the acceptable life safety risks". Indeed, in the opinion of social scientists the public at large would be unlikely to accept higher failure rates than associated with current best practice [51], even if they are based on rational acceptance criteria such as the MLSC principle. For these reasons, the present study explores life safety risk-related acceptance criteria associated with building structures compliant with current best practice, in turn reflected by the structural design codes in force. Risk acceptability therefore depends on the degree of reliability implicitly required by these codes. This degree is unknown and, as previous studies show, might differ fundamentally from nominal target ceilings established in the codes $[30,50]$.

Structural design codes such as [20] offer a variety of possible measures to counteract the effects of accidental actions in building structures [16,31], based on the general performance requirement, that "the structure shall be designed and executed in a way that it will not be damaged to an extent disproportionate to the original cause". Among those measures, one might quote prescriptive design and detailing rules foreseen to enhance structural redundancy and/or robustness. Other strategies are related to the mitigation of consequences such as tolerating local member failure, provided alternative load paths might develop which ensure the overall stability of the structural system. Although it might not be an attractive solution from an economical point of view, design of structural members to withstand the effects of an accidental action constitutes another possible risk-reduction measure. For this purpose, the codes offer specific accidental design rules. Hence, in analogy to the persistent design situations, the failure probabilities associated with cross-sections or members designed for the accidental situation, might be referred to as intrinsically acceptable by the current legislation. This applies as well to the corresponding structure-related risks. The inference of requirements for structural safety is based on this appreciation. The effect of prescriptive code rules for enhancing redundancy and/or robustness on structure-related risks is not investigated in the present study.

\subsection{Mathematical framework}

A mathematical framework for the quantification of structure-related risks is defined in line with the main principles established in prior studies [50,51]. These principles are based on the state of knowledge regarding explicit approaches for the analysis and assessment of risks associated with technical systems. In the present context, such a system is described by a particular building structure. Each of the $n_{j}$ hazard scenarios associated with this structure is 
represented by a specific collapse scenario triggered by failure of one of its $n_{m}$ principle loadbearing members. Such a failure, in turn, is characterized by a specific failure mode that is induced by a particular load arrangement. The $\mathrm{n}_{\mathrm{j}}$ hazard scenarios are mathematically described by their occurrence probabilities $\mathrm{p}_{\mathrm{j}}$ and the associated consequences to persons, in terms of the expected number of collapse-induced fatalities, $\mathrm{N}_{\mathrm{j}}$. Assuming statistical independency between the $\mathrm{j}=1,2, \ldots, \mathrm{n}_{\mathrm{j}}$ hazard scenarios, these can be represented in a so-called risk profile (Fig. 1). In such a risk profile, the $n_{j}$ hazard scenarios are arranged according to the magnitude of the consequences $\mathrm{N}_{\mathrm{j}}$, represented on the axis of abscissa. The axis of ordinates represents the occurrence probabilities $\mathrm{p}_{\mathrm{j}}$ of the scenarios. The integral of the risk profile (Eq. 1) corresponds to the risk $\mathrm{R}$ associated with the structure in question. The occurrence probabilities $\mathrm{p}_{\mathrm{j}}$, and hence the risks $\mathrm{R}$, are associated with a specific reference period.

$R=\sum_{j=1}^{n_{j}} p_{j} \cdot N_{j}$

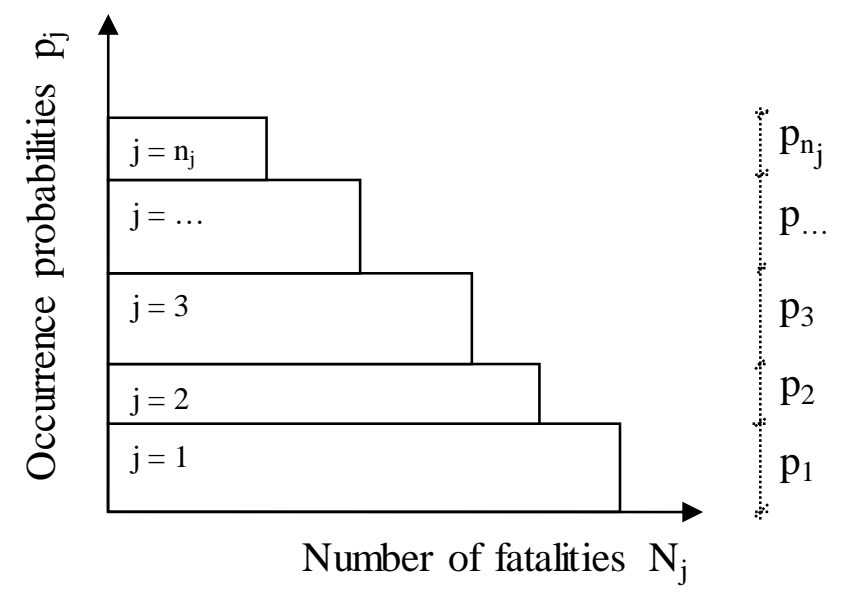

Fig. 1. Schematic representation of a probability-consequence diagram (risk profile).

\subsection{Procedure}

A procedure has been established that comprises the definition of the tasks to be addressed in the present study (Fig. 2). The procedure initially requires the definition of the general context, scope and objectives of the study (step 1), addressed before in Sections 1 and 2.1. The necessary mathematical framework for the estimation of structure-related risks (step 2) was briefly described in Section 2.2.

With the principle aim to cover the majority of the cases encountered in practice, step 3 subsequently involves selecting representative sets of hypothetical but realistic building structures and their constitutive members (Section 3.1). A qualitative risk analysis is then carried out (Section 3.2) with the principal aim to identify the relevant hazard scenarios (j) associated with these structures (step 4).

The occurrence probabilities $\left(\mathrm{p}_{\mathrm{j}}\right)$ of the identified hazard scenarios (Fig. 1) are expressed in terms of the implicitly acceptable member failure probabilities, which represent the degree of reliability implicitly required by the structural design codes (Section 2.1). The determination of this degree corresponds to step 5 of the procedure and implies the following sub-steps (Section 4): 
- Subsequent to their qualitative description, the hazard scenarios are represented in terms of limit state functions (LSF's). With a few exceptions, these LSF's are based on the accidental member design rules as specified in the Spanish design codes employed in the present study $[9,10,13]$. In practice, these codes are compatible with the respective Eurocodes [18-21]. The mentioned exceptions are introduced in order to consider in an explicit manner certain aspects, which in the applied code rules, if at all accounted for, are being addressed in an implicit way. This concerns particularly the dynamic effects (inertia forces, energy dissipation and strain rate effects) due to the relatively high loading rates gas explosions might entail. The defined LSF's accommodate such effects (Section 4.1).

- Based on the established LSF's, the selected structural members are designed following the rules of the codes used. This is adressed in Section 4.2. Inasmuch as conservative design has a significant effect on the level of reliability, it is performed strictly $\left(E_{d}=R_{d}\right)$. Strict design means that the provided design value for structural resistance $R_{d}$ complies exactly with the design value for the considered action effects $E_{d}$.

- Section 4.3 summarizes the characterization of the basic variables involved in the LSF's. Special attention is being paid to the representation of the mentioned dynamic structural effects. Such effects are being quantified by means of a dynamic analysis based on efficient, simplified models.

- A reliability analysis for each of the defined structural members and associated hazard scenarios is carried out (Section 4.4). Taking account of the occurrence probability of gas explosions, the implicitly acceptable failure probabilities are derived.

The estimation of the structural failure consequences according to step 6 of the procedure demands a suitable model. Such a model should deliver estimations for the number of fatalities $\mathrm{N}_{\mathrm{j}}$ due to a specific hazard scenario as a function of the associated magnitude of structural damage. Section 5 addresses the corresponding developments based on a database of explosion-induced collapse events.

As a function of both, $p_{j}$ and $\mathrm{N}_{\mathrm{j}}$, the risk profiles (Fig. 1) for the selected building structures are established in step 7 (Section 6.1). This is done under the inclusion of hazard scenarios associated with normal loading conditions, considering the results of prior studies [50,51]. The integration of the risk profiles according to Eq. (1) delivers the implicitly acceptable life safety risks $\mathrm{R}$ associated with each of the defined structures. Finally, structural safety requirements are deduced from the findings (step 8) and discussed in Section 6.2. 


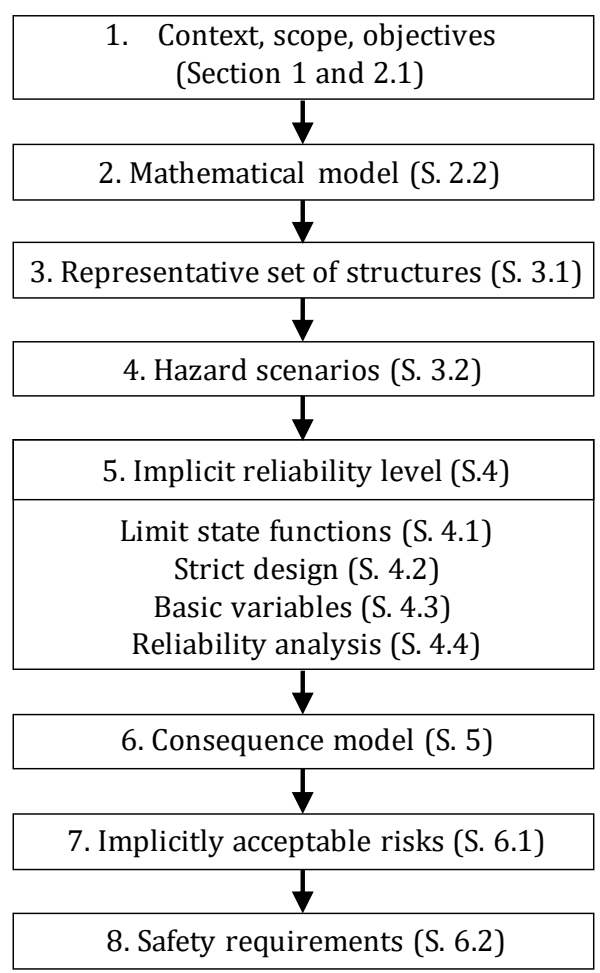

Fig. 2. Procedural flow-chart.

\section{Structures and hazard scenarios}

\subsection{Selection of structures and members}

The study covers RC building structures such as shown in Fig. 3. The buildings are intended for residential use, where gas is being burnt for purpose of energy supply. Overall stability against horizontal influences, such as wind loads, is provided by a rigid concrete core. The principle elements in charge of bearing the gravitational loads are columns, spaced at a distance $\mathrm{L}$ in the longitudinal sense of the structure, and beams spanning this distance (see Fig.4). The beams give support to a floor system (secondary beams or slabs) with a span of $\mathrm{L} / 2$ between the principal frames in transverse sense of the buildings. For sake of simplicity, and since it is a conservative approach with regard to the reliability level, the study is limited to statically determinate members. In order to define a representative set of such members, the nominal values for the relevant design parameters are varied as follows [30].

The study considers beams with spans between $\mathrm{L}=5$ and $40 \mathrm{~m}$. Columns of $4 \mathrm{~m}$ height support the self-weight of $n_{s}=0$ to 30 storeys situated above the member in question. The characteristic concrete compressive strength of the members varies between $\mathrm{f}_{\mathrm{ck}}=25$ and 50 $\mathrm{N} / \mathrm{mm}^{2}$. For the reinforcing steel class B500 $\left(\mathrm{f}_{\mathrm{yk}}=500 \mathrm{~N} / \mathrm{mm}^{2},\left(\mathrm{f}_{\mathrm{t}} / \mathrm{f}_{\mathrm{y}}\right)_{\mathrm{k}}=1.08, \varepsilon_{\mathrm{uk}}=5 \%\right)$ is considered [21]. The characteristic values for the permanent loads of the floor system (excluding self-weight of the principle beams) reach from $g_{f, k}=0.5$ to $13 \mathrm{kN} / \mathrm{m}^{2}$. The selfweight of the roof system (excluding self-weight of the principle beams) is accounted for by load $\mathrm{g}_{\mathrm{rk}}$, varying between 1 and $10 \mathrm{kN} / \mathrm{m}^{2}$. Imposed loads of $\mathrm{q}_{\mathrm{i}, \mathrm{k}}=2 \mathrm{kN} / \mathrm{m}^{2}$ are considered in line with the residential use assumption. In addition, the study distinguishes snow-loads on the roof ranging from $\mathrm{q}_{\mathrm{s}, \mathrm{k}}=1.5$ to $3 \mathrm{kN} / \mathrm{m}^{2}$. The design explosion load is defined 
according to Annex D.2 of EN 1991-1-7 [20] as a function of the venting coefficient $A_{v} / V$ and the static activation pressure of the vents, $\mathrm{p}_{\text {stat. }}$ The corresponding parameter selection $\left(\mathrm{A}_{\mathrm{v}} / \mathrm{V}=0.05\right.$ to $0.15 \mathrm{~m}^{-1}$ and $\mathrm{p}_{\text {stat }}=2$ to $\left.7 \mathrm{kN} / \mathrm{m}^{2}\right)$ covers design values for explosion pressures up to $p_{E X, d}=23 \mathrm{kN} / \mathrm{m}^{2}$. A direct transfer of the uniformely distributed pressure from the closures of the explosion compartment (floors, ceilings and walls) to the adjacent loadbearing structural members is assumed. For that purpose it is assumed that local confinement of the pressure by the closures will contribute to smaller tributary areas than considered for the gravitational loads.

The combination of the described parameters within the indicated ranges leads to a representative set of $486 \mathrm{RC}$ beams and $28512 \mathrm{RC}$ columns. Selected members out of these sets constitute a total of different $4512 \mathrm{RC}$ building structures with varying number of constitutive members $\left(\mathrm{n}_{\mathrm{m}}=6\right.$ to 40931$)$ and net room areas $\left(A=200\right.$ to $\left.990000 \mathrm{~m}^{2}\right)$.

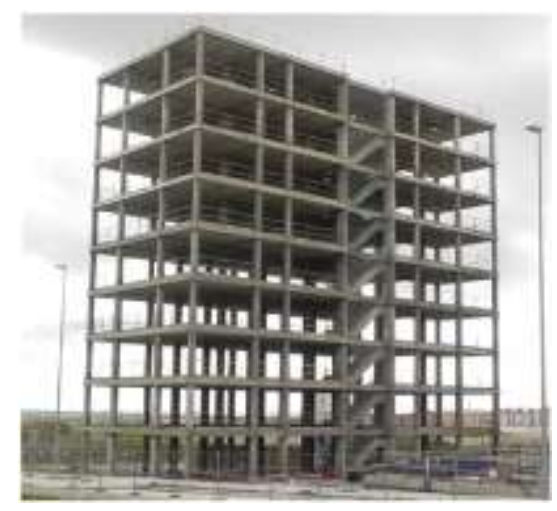

Fig. 3. Representative building structure with RC members.

\subsection{Hazard scenarios}

\subsubsection{Member load arrangements and failure modes}

Accidental load arrangements for the RC beams are defined under consideration of gravitational loads acting simultaneously to the explosion pressure [30]. Two relevant load arrangements are distinguished for the floor beams (see Fig. 4). Load arrangement $\mathrm{p}_{\mathrm{EX}(+)}$ is relevant for beams supporting the bottom floor system of the enclosure where the explosion occurs. This system is subjected to an explosion-induced load pex which adds to the previously present gravitational loads $(\mathrm{g}+\mathrm{q})$. In addition, load arrangement $\mathrm{p}_{\mathrm{EX}(-)}$ concerns the beams supporting the ceiling of the enclosure where the explosion occurs, submitted to a blast load $p_{E X}$ which counteracts the gravitational loads. Since in this case the contribution of the latter to the resulting action effects is favorable, only permanent loads $g$ are considered $(\mathrm{q}=0)$. 


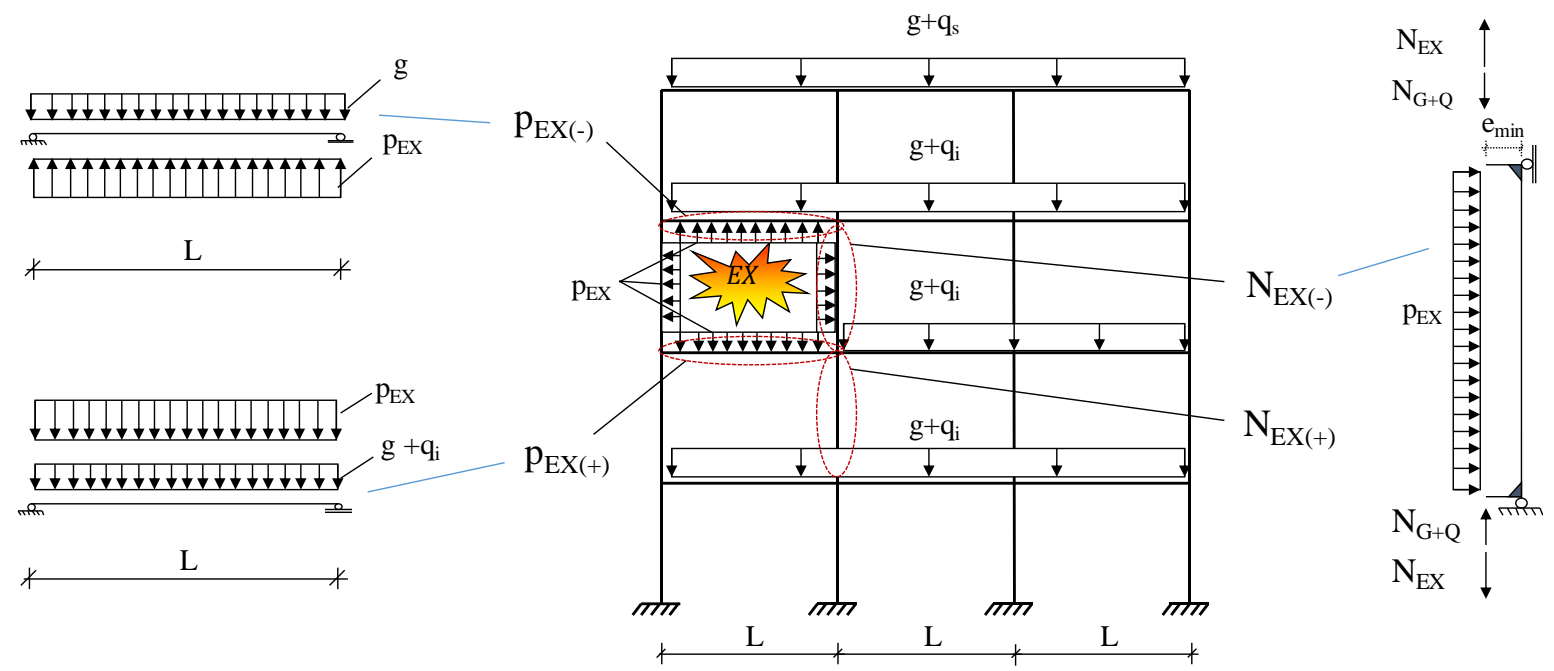

Fig. 4. Load arrangements $\mathrm{p}_{\mathrm{EX}(+)}, \mathrm{p}_{\mathrm{EX}(-)}$ and $\mathrm{N}_{\mathrm{EX}(-)}$ considered in the study

Load arrangement $\mathrm{p}_{\mathrm{EX}(+)}$ is considered relevant for positive bending failure $\left(\mathrm{M}_{(+)}\right)$at midspan of the beams. Moreover, situation $\mathrm{p}_{\mathrm{EX}(+)}$ is critical for shear failure at the beam support cross-section. Failure of the compression strut $\left(\mathrm{V}_{\mathrm{c}}\right)$ and the tension tie $\left(\mathrm{V}_{\mathrm{s}}\right)$ is distinguished. In addition to $\mathrm{p}_{\mathrm{EX}(+)}$, the consideration of load arrangement $\mathrm{p}_{\mathrm{EX}(-)}$ is justified in case the action effects induced by the explosion loading $\mathrm{p}_{\mathrm{EX}}$ equal at least those due to the permanent loads (g). Under this assumption, a potential negative bending failure $\left(\mathrm{M}_{(-)}\right)$at the mid-span cross section of the beams is investigated. In turn, a shear failure due to load arrangement $\mathrm{p}_{\mathrm{EX}(-)}$ is considered to be comparatively unlikely. In practice, design for shear will be governed either by the persistent situations or by the accidental load arrangement $\mathrm{p}_{\mathrm{EX}(+)}$, where the explosion load is added to the gravitational loads. Consequently, shear failure under load arrangement $p_{E X(-)}$ is not accounted for in the study.

The most relevant load arrangement in view of the analysis of the columns is termed $\mathrm{N}_{\mathrm{EX}(-)}$ (Fig. 4). The columns, situated in the alignments of the vertical closures confining the compartment where the explosion occurs, are subjected to a blast-induced tensile axial force component $\mathrm{N}_{\mathrm{EX}}$. This force counteracts the previously acting compression axial force due to gravitational loads, $\mathrm{N}_{\mathrm{G}+\mathrm{Q}}$. Moreover, the blast induces a horizontal load component pex (Fig. 4).

Under the described influences, the mid-span cross section of the columns might be subject to a potential bending failure in interaction with axial forces (M-N). The bending moment (M) stems from the horizontal, explosion-induced component pex and from the eccentrically acting axial force $(\mathrm{N})$ in the member (Fig. 4). A possible cross-section failure upon reaching the ultimate moment is distinguished from buckling failure of the columns. In addition, load arrangement $\mathrm{N}_{\mathrm{EX}(-)}$ might induce shear failure at the support cross sections of the columns. Again the influence of axial forces on the failure mode is to be accounted for. A distinction is drawn for failure of the compression strut $\left(\mathrm{V}_{\mathrm{c}}-\mathrm{N}\right)$ and the tension tie $\left(\mathrm{V}_{\mathrm{s}}-\mathrm{N}\right)$.

The columns situated below and above the alignments of the vertical closures confining the explosion compartment are subjected to a compression axial force component $\mathrm{N}_{\mathrm{EX}}$, which enhances the initial compression force level in the member, $\mathrm{N}_{\mathrm{G}+\mathrm{Q}}$. Considering an eccentric action of the resulting compression force, this load arrangement, termed $\mathrm{N}_{\mathrm{EX}(+)}$ (Fig. 4), might induce a M-N interaction-controlled failure scenario of the columns. However, the occurrence of such a scenario is considered to be comparatively unlikely and will not be 
accounted for in the present study. This appreciation is supported by a performed design check which showed that load arrangement $\mathrm{N}_{\mathrm{EX}(+)}$ is not found to be decisive for any of the studied columns. The decisive design situation is governed either by the persistent load scenario (only $\mathrm{N}_{\mathrm{G}+\mathrm{Q}}$ ), or by the above-introduced accidental load arrangement $\mathrm{N}_{\mathrm{EX}(-)}$.

\subsubsection{Member failure-induced system collapse}

Simplifying assumptions are adopted to account for the possibility of a partial- or total system collapse scenario induced by a member failure. In general these assumptions are in line with the assumption of statically determinate structural members (Section 3.1). They can be summarized as follows.

A beam failure is supposed to induce immediate loss of equilibrium of the secondary floor system (secondary beams or slabs) to which it provides support. In addition, due to falling debris, the beam collapse will affect the area of the floor situated immediately below, without inducing its collapse, however. In the same way, the loss of a specific column would give rise to the immediate collapse of the columns corresponding to the same alignment in the floors above, and necessarily of the floor systems supported by these. A column collapse will not entail a progressive collapse of the floors below.

Moreover, the lack of structural continuity associated with the assumption of statically determinate members implies that a member collapse will not entrain and drag down structural elements situated in adjacent frames. Such a behavior could be observed in explosion-induced collapse scenarios of continuous structural systems [8, 45].

\section{Implicit reliability level}

\subsection{Limit state functions}

Following their qualitative description, the identified hazard scenarios are translated into LSF's. A complete description of these functions is given in [30]. As an example, Eq. (2) shows the limit state corresponding to bending failure at mid-span of the beams, expressing equilibrium between the acting and the resisting moment, respectively, $M_{E}$ and $M_{R}$. Eq. (2) is valid for both bending failure modes $\mathbf{M}_{(+)}$and $\mathbf{M}_{(-)}$induced by load arrangements $\mathrm{p}_{\mathrm{EX}(+)}$ and $\mathrm{p}_{\mathrm{EX}(-)}$, respectively (Fig. 4). In case of the former, the moments due to the static loads ( $\mathrm{M}_{\mathrm{G}}$ due to permanent loads $\mathrm{g}$ including self-weight and $\mathrm{M}_{\mathrm{Q}}$ due to imposed loads $\mathrm{q}_{\mathrm{i}}$ ) are added to the dynamic, explosion-induced moment $\mathrm{M}_{\mathrm{EX}}$. For the latter, moment $\mathrm{M}_{\mathrm{G}}$ is rested from $\mathrm{M}_{\mathrm{EX}}$ (and $\mathrm{M}_{\mathrm{Q}}=0$ ). Coefficient $\psi_{1}$ is adopted from $[10,18]$ and introduced in the LSF as a simplification to account for combination of variable actions in accidental situations, respectively.

$\xi_{M_{R}} \cdot\left(F_{s 1} \cdot d-\frac{k_{c}}{a_{c}} \cdot \frac{F_{s 1}{ }^{2}}{b \cdot \alpha_{c c} \cdot f_{c, d y n}}\right)-\left(\xi_{M_{E, s t a t}} \cdot\left(\mp M_{G}+\Psi_{1} \cdot M_{Q}\right)+\xi_{M_{E, d y n}} \cdot M_{E X}\right)=0$

The resisting moment $M_{R}$ is function of force $F_{s 1}$ in the tensile reinforcing steel layer $A_{s 1}$ (Fig. 5). For the steel, a bi-linear stress-strain law including strain-hardening is assumed. Parameters $k_{c}$ and $a_{c}$ define the parabola-rectangle law adopted for concrete under compression (Fig. 5). The definition of the material parameters of both steel and concrete take account of the dynamic stress rates induced by gas explosions. Coefficients $\xi$ account 
for uncertainties associated with the models for determining action effects $\left(\mathrm{M}_{\mathrm{E}}\right)$ and resistance $\left(M_{R}\right)$, respectively.

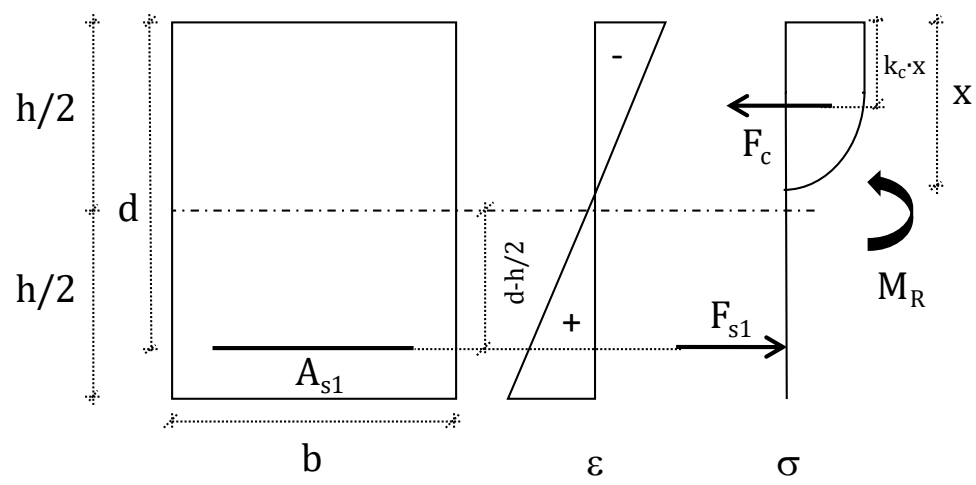

Fig. 5. Cross-section characteristics.

\subsection{Strict design}

Based on the established LSF's, the selected structural members are strictly designed $\left(E_{d}=\right.$ $\mathrm{R}_{\mathrm{d}}$ ) for the accidental design situation specified in the codes employed (see Section 2.3). In addition, where relevant, a design of the same members according to the persistent situations, which refer to conditions of normal use, is carried out based on the hazard scenarios defined in previous studies $[28,50,52]$. Out of both, the decisive situation is subsequently identified. This is important for in many practical situations the persistent situations might require a higher structural resistance than the accidental scenario, a fact that significantly influences the member reliability level. For instance, concerning positive bending failure of the beams $\left(\mathrm{M}_{(+)}\right)$, the strict design leads to 213 out of the initially defined 486 beams that are governed by the accidental situation. In the remaining 273 cases the persistent design situation is decisive [30].

\subsection{Characterization of basic variables}

In a prior study [52], probabilistic models for the most relevant structural design variables were deduced. They represent the uncertainty associated with the rules laid down in the herein used design codes. Further information can be found in Annex A of fib bulletin 80 on partial factor methods for existing concrete structures [25]. Important to state here that these models were derived in the context of persistent design situations. Nevertheless, some may also be adopted for a reliability analysis in connection with gas explosions. Models established for static load variables, or referring to the geometric dimensions of structural members, for instance, require no modification for use in the context of accidental situations.

The dynamic action effects $\mathrm{E}_{\mathrm{EX}}$ induced by the gas explosion (e.g. bending moments $\mathrm{M}_{\mathrm{EX}}$ ) are deduced from Eq. (3). In this equation, EEX,peak represents the action effect which would result from the statically applied peak explosion pressure peX,peak of the time-dependant explosion pressure function $\mathrm{p}_{\mathrm{EX}}(\mathrm{t})$ (Fig. 6). The dynamic load factors DLF $\mathrm{E}_{\mathrm{E}}$ take account of dynamic effects on the structural behavior during blast load exposure, such as the contribution of inertia forces and energy-dissipation due to plastic deformations.

$\mathrm{E}_{\mathrm{EX}}=\mathrm{DLF}_{\mathrm{E}} \cdot \mathrm{E}_{\mathrm{EX}, \text { peak }}$ 


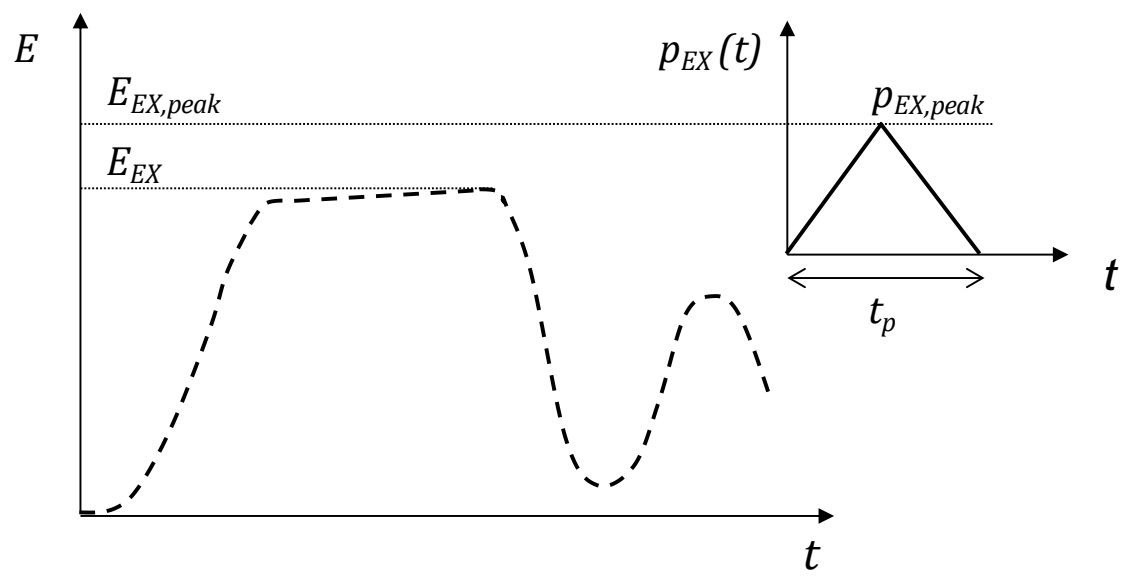

Fig. 6. Illustration of relation between dynamic, explosion induced action effect $E_{\mathrm{EX}}$ and corresponding value $\mathrm{E}_{\mathrm{EX}, \text { peak }}$ due to statically applied peak-load $\mathrm{p}_{\mathrm{EX}, \text { peak }}$

For the purpose of deriving a probabilistic model for the peak pressure pEX,peak, the results of Dragosavic's full scale tests [12] are subjected to a statistical analysis. These tests constitute the basis of the current design load model in Annex D.2 of EN 1991-1-7 [20]. A total of 15 test results within ranges for venting coefficiens $A_{v} / V$ between 0.05 and $0.15 \mathrm{~m}^{-1}$ and static

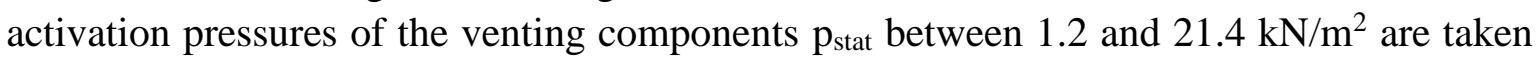
into account in the analysis. Regression analysis is conducted to find the functions best rep-

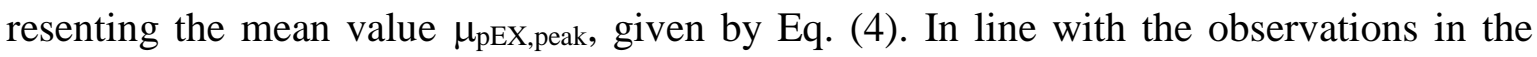
experimental survey [12] and with the formulation of the design load model in EN 1991-17 [20], Eq. (4) distinguishes two explosion load pulses and depends on both $A_{v} / \mathrm{V}$ and $\mathrm{p}_{\text {stat. }}$.

$\mu_{\mathrm{p}_{\mathrm{EX}, \text { peak }}}=-16.4+0.6 \cdot p_{\text {stat }}+\frac{3.6}{\left(\frac{A_{v}}{V}\right)^{0.8}}>\mathrm{e}^{\left(0.33+0.55 \sqrt{p_{\text {stat }}}\right)}$

It should be mentioned that a model predicting similar mean peak pressures was suggested earlier by Leyendecker and Ellingwood [37]. On the contrary, Schmidt proposed a model based on Computational Fluid Dynamics (CFD) [43] that predicts far higher explosion pressures across the entire range of $A_{v} / \mathrm{V}$. This circumstance can be probably traced back to the influence of random parameters which Schmidt studied in detail. Among these parameters are the location of the point of ignition with respect to the gas cloud and the venting components, or obstacle-induced turbulences. On the contrary, the herein derived model $\mu_{\mathrm{pEX} \text {,peak }}$ is conservative with regard to the gas concentration, for in all the tests considered in the present study, a homogenously distributed, stoichiometric gas-oxygen mixture was ignited [12]. All in all, the obtained model is judged to provide a fairly well estimate of the expected peak pressure in a gas explosion event.

The fitting of a statistical distribution to the explosion pressure is a difficult exercise due to the short number of available test results. Further to the central limit theorem, Schmidt assumed $p_{E X, p e a k}$ to be normally distributed [43], as did Leyendecker and Ellingwood [37]. Vrouwenvelder et al. [59] adopted a lognormal distribution in the context of a numerical example addressed to the analysis of robustness measures in a residential building. A lognormal distribution was likewise adopted in the present study. Based on this assumption and an analysis of the scatter of the considered test results, a coefficient of variation of 0.7 was found to adequately represent the uncertainties associated with generation of the explosion

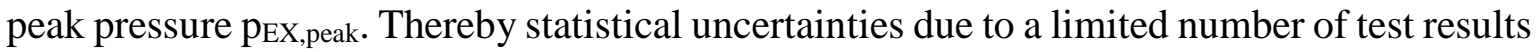
were accounted for. A coefficient of variation of 0.7 is likewise recommended in $[58,59]$, 
based on a comparison of the Eurocode design load model to test results by Zeeuwen and Van Wingerden [61].

The DLFE in Eq. (3) depend on the characteristics of both the explosion load and the structural behaviour. Based on observations in experimental and numerical studies [12, 43], the load can be reasonably represented as an idealized, triangular pressure-time function (Fig. 6). The assumed load pulse duration $t_{p}$, varies between 0.2 and $0.5 \mathrm{~s}$, depending on the volume of the enclosure where the explosion occurs $[3,4]$. The idealization of the explosion load by means of a pressure-time function enables the use of well established simplified dynamic models $[5,53]$. These are applied in a deterministic structural analysis (based on mean values for the material properties) to determine the expected $\operatorname{DLF}_{\mathrm{E}}[27,29]$. For flexural response, the DLF $_{M}$ are obtained assuming a single degree of freedom (SDOF) system. Therefore, an elasto-plastic dynamic resistance function deduced from momentcurvature $(\mathrm{M}-\chi)$ analysis under consideration of dynamic material properties (see below) is assumed. The shear-related $\mathrm{DLF}_{\mathrm{V}}$ are determined from the dynamic equilibrium applied to the members themselves. The $\mathrm{DLV}_{\mathrm{V}}$ also account for the fact that shear failure close to the member support may arise before a plastic hinge at the mid-span cross-section is being developed. For the beams under load arrangement $\mathrm{p}_{\mathrm{EX}(+)}$, for instance, it was observed that at the time of shear failure, on average only about $1 / 3$ of the energy dissipation capacity corresponding to the flexural failure mode is taken advantage of. This and other findings from the simplified dynamic analysis were validated by means of a numerical study [29].

Predicting the dynamic load effects as described is obviously subject to model uncertainties. These are factored to the $\mathrm{DLF}_{\mathrm{E}}$ by means of coefficients $\xi_{\mathrm{E} \text {,dyn }}$, characterized by a log-normal distribution, with mean $\mu_{\xi \mathrm{E} \text {,dyn }}=1.0$ and standard deviation $\sigma_{\xi \mathrm{E} \text {,dyn }}$ (Fig. 7a). The choice of $\sigma_{\xi \mathrm{E}, \mathrm{dyn}}$ is based on test observations $[38,41,60]$ and/or subjective estimations $\left(\sigma_{\xi \mathrm{M}, \mathrm{dyn}}=0.2\right.$, $\sigma_{\xi \mathrm{V}, \mathrm{dyn}}=0.3, \sigma_{\xi \mathrm{N}, \mathrm{dyn}}=0.05$, for bending moments, shear and axial forces, respectively).
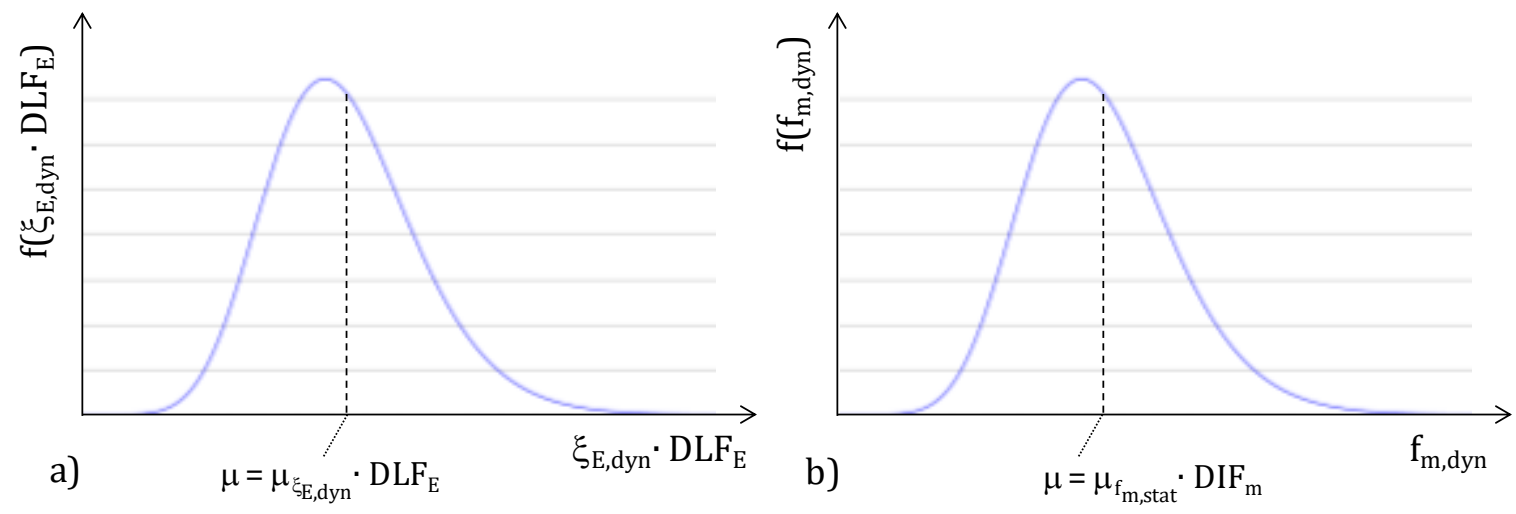

Fig. 7. Log-normal probability density function for dynamic load factor $\mathrm{DLF}_{\mathrm{E}}$ including model uncertainty $\xi_{\mathrm{E}, \mathrm{dyn}}$ (a) and for dynamic strength variable $\mathrm{f}_{\mathrm{m}, \mathrm{dyn}}(\mathrm{b})$.

The mean values $\mu_{\mathrm{m} \text {,dyn }}$ of the mechanical properties (strength, strain and modulus) of concrete and steel under high loading rate exposure (strain rate effects) are represented as the product of the corresponding mean values associated with quasi-static loading, $\mu_{\mathrm{m}, \mathrm{stat}}$, and dynamic increase factors, $\mathrm{DIF}_{\mathrm{m}}$. The $\mathrm{DIF}_{\mathrm{m}}$ are determined by means of simplified

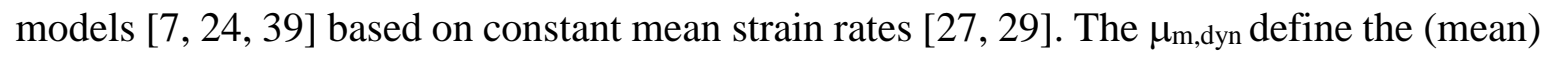
stress-strain relationships of concrete and steel under dynamic, explosion-induced loading. As far as strength variables $\mathrm{f}_{\mathrm{m} \text {,dyn }}$ are concerned (Fig. $7 \mathrm{~b}$ ), such as the concrete compressive 
strength $f_{c, d y n}$, the reinforcing steel yield- and tensile strength, respectively, $f_{y, d y n}$ and $f_{u, d y n}$, the corresponding coefficient of variation $\left(\mathrm{CoV}_{\mathrm{fm}, \mathrm{dyn}}\right)$ is assumed to be the same as in the respective properties under quasi-static loading exposure [52]. Concerning $f_{c, d y n}$, experimental evidence supporting this assumption is provided in [40].

\subsection{Reliability analysis}

The FORM implemented in VaP [42], delivers the implicitly admissible, conditional probabilities $\mathrm{p}_{\mathrm{f}, \mathrm{adm}} \mid \mathrm{Ex}$ for the members to fail given the occurrence of a gas explosion within the established reference period ( $\mathrm{T}_{\mathrm{ref}}=50$ years). Under the assumption of a uniform distribution in time, the occurrence rate $\mathrm{p}(\mathrm{EX})$ of a gas explosion in $\mathrm{T}_{\text {ref }}$ can be reasonably modeled by a Poisson process, depending on the annual probability of an explosion event per gas-supplied housing unit, $\lambda$ [58]. The good correlation among the findings reported in studies conducted in different countries and different time periods $[1,6,14,17,37,43,58$, 59] allows for an assumption of $\lambda \approx 10^{-5} \mathrm{y}^{-1}$. Using this figure, the implicitly admissible failure probabilities $\mathrm{p}_{\mathrm{f}, \mathrm{adm}, \mathrm{EX}}$ associated with $\mathrm{T}_{\text {ref }}$ are established by Eq. (5). In terms of Eq. (1), the $\mathrm{p}_{\mathrm{f}, \mathrm{adm}, \mathrm{EX}}$ represent the occurence probabilities $\mathrm{p}_{\mathrm{j}}$ of the accidenal hazard scenarios associated with a particular building structure.

$\mathrm{p}_{\mathrm{j}} \equiv \mathrm{p}_{\mathrm{f}, \mathrm{adm}, \mathrm{EX}}=\mathrm{p}(\mathrm{EX}) \cdot \mathrm{p}_{\mathrm{f}, \mathrm{adm} \mid \mathrm{EX}}=\left(1-\mathrm{e}^{-\lambda \cdot \mathrm{T}_{\mathrm{ref}}}\right) \cdot \mathrm{p}_{\mathrm{f}, \mathrm{adm} \mid \mathrm{EX}} \cong \lambda \cdot \mathrm{T}_{\mathrm{ref}} \cdot \mathrm{p}_{\mathrm{f}, \mathrm{adm} \mid \mathrm{EX}}$

A detailed discussion of the implicitly required reliability indices $\beta_{\text {req,EX converted from }}$ failure probabilities $\mathrm{p}_{\mathrm{f}, \mathrm{adm}, \mathrm{EX}}$ is given in [30]. Table 1 gives a summary of the results corresponding to the different structural member types and failure modes analysed. It can be observed that the mean values $\mu_{\beta}$ are generally relatively high. With one exception, they are found to be larger than the nominal target reliability index required by the codes, $\beta_{\mathrm{t} \text {,code }}=3.8$ $[10,18]$. However, the results are also affected by an important scatter as attested to by the represented fractions corresponding to reliability indices $\beta_{\text {req,EX }}$ below $\beta_{\mathrm{t} \text {,code }}=3.8$ (based on

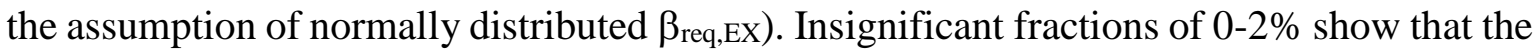
reliability level associated with a shear failure of the compression strut at the beam or column support cross-section is comparatively high. On the contrary, the shear failure of the tension tie turns out to be especially critical with an estimated fraction $\beta_{\text {req,EX }}<\beta_{\text {t,code }}$ of about $30 \%$ for the beams and $70 \%$ of the columns. Concerning bending failure, this fraction oscillates between 11 and $18 \%$.

Almost irrespective of the member type and failure mode, the highly uncertain explosioninduced action effects have a dominant influence on the reliability level. This is especially true if the ratio between explosion load and total loads is relatively high. In general, the results obtained point to scope for improvement of current design rules.

\section{Table 1}

Statistical evaluation of reliability index $\beta_{\text {req,Ex }}$ for studied members strictly designed according to the decisive design situation $\left(\mathrm{T}_{\text {ref }}=50\right.$ years $)$.

\begin{tabular}{ccccccc}
\hline $\begin{array}{c}\text { Element } \\
\text { type }\end{array}$ & Cross-section & Failure mode & Load arrangement & $\begin{array}{c}\mathrm{N}^{\text {o }} \text { of } \\
\text { results }\end{array}$ & $\mu_{\beta \text { req,EX }}$ & $\beta_{\text {req,EX }}<3.8^{*}$ \\
\hline \multirow{3}{*}{ Beams } & Mid-span & $\mathrm{M}_{(+)}$ & $\mathrm{p}_{\mathrm{EX}(+)}$ & 486 & 4.3 & $17 \%$ \\
& & $\mathrm{M}_{(-)}$ & $\mathrm{p}_{\mathrm{EX}(-)}$ & 136 & 4.0 & $18 \%$ \\
& \multirow{2}{*}{ Support } & $\mathrm{V}_{\mathrm{c}}$ & $\mathrm{p}_{\mathrm{EX}(+)}$ & 486 & 4.7 & $2 \%$ \\
& & $\mathrm{~V}_{\mathrm{s}}$ & $\mathrm{p}_{\mathrm{EX}(+)}$ & 486 & 4.0 & $30 \%$
\end{tabular}




\begin{tabular}{|c|c|c|c|c|c|c|}
\hline \multirow{3}{*}{ Columns } & Mid-height & M-N & $\mathrm{N}_{\mathrm{EX}(-)}$ & 28512 & 6.5 & $11 \%$ \\
\hline & \multirow{2}{*}{ Support } & $\mathrm{V}_{\mathrm{c}}-\mathrm{N}$ & $\mathrm{N}_{\mathrm{EX}(-)}$ & 28512 & 4.5 & $0 \%$ \\
\hline & & $\mathrm{V}_{\mathrm{s}}-\mathrm{N}$ & $\mathrm{N}_{\mathrm{EX}(-)}$ & 28152 & 3.7 & $70 \%$ \\
\hline
\end{tabular}

* Based on assumption that $\beta_{\text {req,EX }}$ is normally distributed

\section{Consequence model}

As stated in Section 2.3, the estimation of the failure consequences in terms of the number of fatalities $\mathrm{N}_{\mathrm{j}}$ due to a specific collapse scenario $\mathrm{j}$ calls for a practical model. This model should consider the magnitude of structural damage associated with the scenario $\mathrm{j}$. Previous work showed that this link can be suitably established by damage parameter $\mathrm{A}_{\text {col }}$, which represents the building area affected by the collapse [50, 51]. Taking account of the established hypothesis for the extensions of a system collapse scenario given a local member failure (Section 3.2.2), the area affected in such a scenario, $\mathrm{A}_{\mathrm{col}, \mathrm{j}}$, can be defined in terms of the parameters describing the global geometry of the building structure and the specific member location within this structure by means of Eq. 6 and 7 below.

$A_{c o l, j}=C_{b} \cdot L^{2} \quad$, for collapse triggered by beam failure

$\mathrm{A}_{\mathrm{col}, \mathrm{j}}=\mathrm{C}_{\mathrm{c}} \cdot \mathrm{L}^{2} \cdot \mathrm{n}_{\mathrm{s}, \mathrm{col}, \mathrm{j}} \quad$, for collapse triggered by column failure

Where:

$\mathrm{C}_{\mathrm{b}}$ : Constant accounting for location of collapse-triggering beam: $\mathrm{C}_{\mathrm{b}}=0.5$ for roof beams situated on the building perimeter; $\mathrm{C}_{b}=1.0$ for roof beams situated inside the building perimeter or floor beams on the building perimeter; $\mathrm{C}_{\mathrm{b}}=2$ for floor beams situated inside the building perimeter.

$\mathrm{C}_{\mathrm{c}}$ : Constant accounting for location of collapse-triggering column; $\mathrm{C}_{\mathrm{b}}=0.5$ for columns situated on the corners of the building perimeter; $\mathrm{C}_{\mathrm{b}}=1.0$ for columns situated on the building perimeter except the corners; $\mathrm{C}_{\mathrm{b}}=2$ for columns situated inside the building perimeter

L: $\quad$ Distance between axes of columns in longitudinal sense of the building (Fig. 4)

$n_{s, c o l, j}:$ Number of storeys affected by the collapse of the column (includes the storey where the column failure occurs and the storeys situated above this, excluding the roof)

In order to establish a relationship between $\mathrm{N}_{\mathrm{j}}$ and $\mathrm{A}_{\text {col, } \mathrm{j}}$ as well as other potential influence variables, data on explosion-induced structural collapse is gathered. The systematic literature and press-survey is limited to collapse scenarios in western countries. For detailed and objective damage descriptions are lacking in many cases, an extremely cautious and tedious analysis of the available information is required to reliably identify a structural collapse scenario and to perform a trustworthy estimate of its extensions. Moreover, data provided by the Spanish National Statistics Institute (INE) [33] is incorporated into the database to complement lacking information. For instance, in many cases INE data allows for estimation of the fundamental damage parameter $\mathrm{A}_{\mathrm{col}, \mathrm{j}}$ as a function of the number of collapsed storeys and/or the number of collapsed housing units.

The data collection and complementation concluded with 91 gas explosion-induced collapse incidents, relevant to the purpose of deriving a consequence model. In the framework of a 
multiple linear regression analysis, a stepwise procedure known as 'backward elimination" is applied. This procedure consists in initially including all the potential explanatory variables and in each subsequent step eliminating the least significant one, as determined by the t-test, based on the t-distribution by Student [32]. A large number of trials is carried out under variation of different combinations and mathematical transformations of these variables. The most significant regression model fitted to the available data, which complies with all essential requirements (linearity, normality, homoscedasticity and independency of the residuals) is given by Eq. (8). The model expresses the expected number of fatalities $\mathrm{N}_{\mathrm{j}}$ as a function of the area affected by the collapse $\mathrm{A}_{\mathrm{col}, \mathrm{j}}\left[\mathrm{m}^{2}\right]$ and the occupancy of this area $\mathrm{Ocu}_{\mathrm{col}, \mathrm{j}}$ (number of persons present on $\mathrm{A}_{\mathrm{col}, \mathrm{j}}$ at the time of collapse). For estimation of the latter, a mean occupancy rate of about 1 person $/ 30 \mathrm{~m}^{2}$ for residential buildings in Spain, found from INE data [33], is adopted here as a representative value for the analyzed structures.

$$
\mathrm{N}_{\mathrm{j}}=0.72 \cdot \mathrm{Ocu}_{\mathrm{col}, \mathrm{j}}{ }^{0.515} \cdot \mathrm{A}_{\mathrm{col}, \mathrm{j}}{ }^{0.051} \quad\left[\mathrm{~A}_{\mathrm{col}, \mathrm{j}} \text { in } \mathrm{m}^{2}\right]
$$

\section{Acceptance criteria}

\subsection{Implicitly acceptable risks}

As a function of the hazard scenario occurrence probabilities $p_{j}\left(\right.$ Eq. 5) and consequences $N_{j}$ (Eq. 7), the implicitly acceptable life safety risks $\mathrm{R}$ associated with each of the 4512 defined building structures (Section 3.1) are computed according to Eq. (1). The risk analysis considers a conditional member exposure probability. This probability accounts for the likelihood that a particular structural member might be out of the influence area of the explosion pressure wave when the incident occurs. Moreover, the analysis accounts for the fact that in addition to the explosion-induced, accidental hazard scenarios $(E X)$, certain member failure modes might be triggered by persistent load arrangements $(P E R)$. The $\mathrm{p}_{\mathrm{j}}$ corresponding to the persistent load scenarios associated with normal building use conditions are adopted from previous studies $[50,51]$.

The implicitly acceptable risk to persons $\mathrm{R}$ associated with each of the 4512 structures are represented in Fig. 8a. The results are shown as a function of the number of failure modes $\mathrm{n}_{\mathrm{k}}$ of all the members constituting the structure in question. Each point represents the risk associated with one structure in a 50 year reference period. The figure clearly reveals a scale effect: As expressed by Eq. (1), risks associated with structures designed in strict accordance with the existing legislation rise with the number of hazard scenarios $n_{j}$, which, in turn, increases with the number of structural members $n_{m}$, failure modes $n_{k}$ (Fig. 8a) and load arrangements $\left(\mathrm{n}_{1}\right)$ that may trigger these failure modes. 

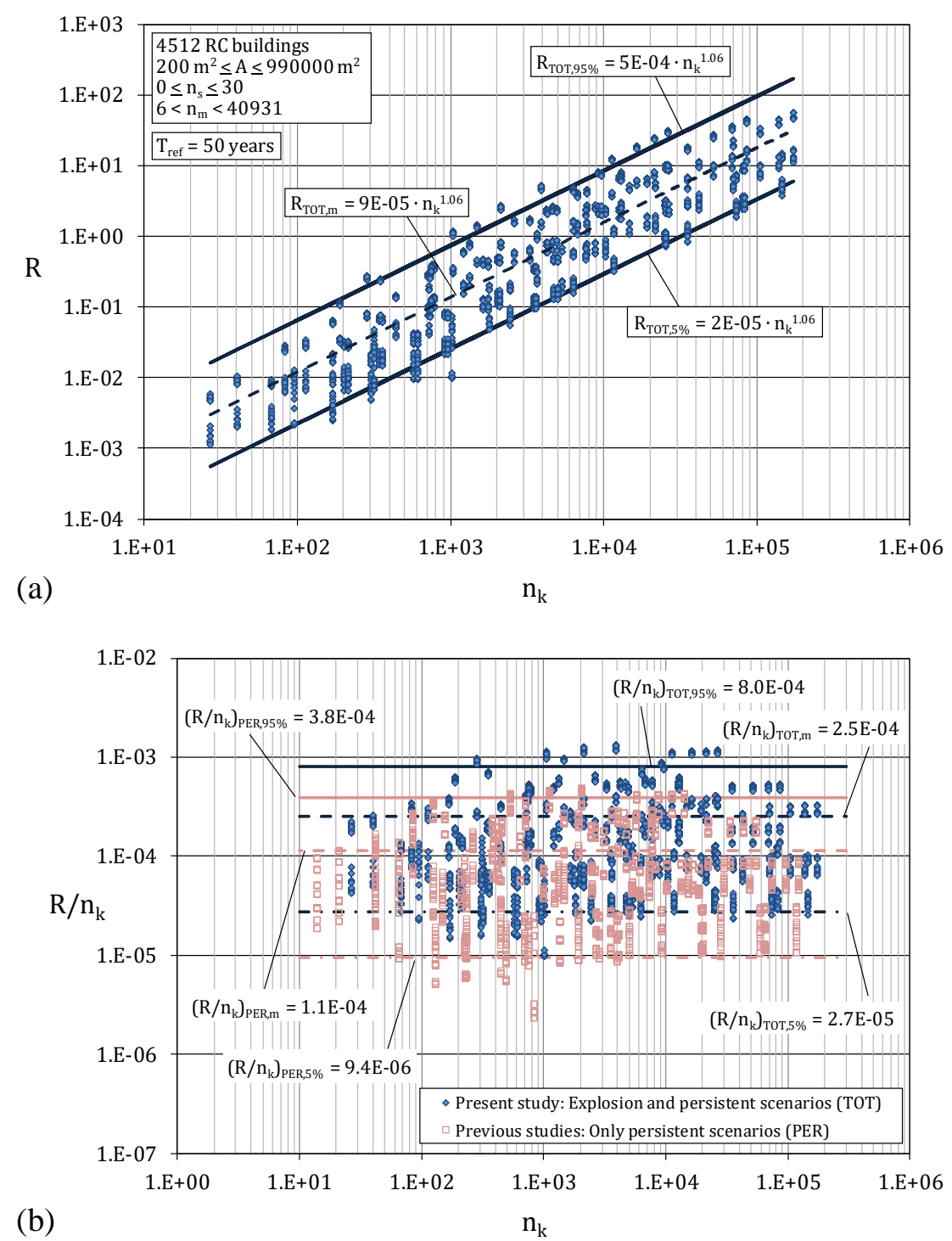

Fig. 8. Risks R vs. $n^{\circ}$ of failure modes $n_{k}$ (a); R normalised for $n_{k} v s . n_{k}$ and comparison to results from prior studies $[50,51](\mathrm{b}) ; \mathrm{T}_{\text {ref }}=50$ years

The mentioned scale effect can be eliminated by normalizing the results as shown in Fig. $8 \mathrm{~b}$. It plots the risks $R$ normalized for the number of failure modes $n_{k}$ versus $n_{k}$ (diamant-shaped dots). Here, too, each point represents the result for one building structure. The relationship between the normalized risks and $\mathrm{n}_{\mathrm{k}}$ can be statistically characterised by a constant mean value, $\left(\mathrm{R} / \mathrm{n}_{\mathrm{k}}\right)_{\text {TOT,m }}$, and an associated scatter, expressed in terms of the lognormal-based $5 \%$

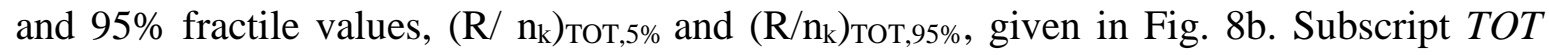
refers here to the total risk due to both persistent and explosion load-induced hazard scenarios. The mean value of the implicitly accepted risks per failure mode, $\left(\mathrm{R} / \mathrm{n}_{\mathrm{k}}\right)_{\mathrm{TOT}} \mathrm{m}$, is of the order of $10^{-4}$. The observed scatter may be attributed, in part, to an incomplete and not fully consistent calibration of the rules for member design laid down in the existing standards.

The obtained risks can be compared to those obtained in prior studies on risks associated with structures exposed exclusively to persistent situations $[50,51]$. The comparison is possible since the methodology followed and the associated basic assumptions adopted in both studies are consistent to each other. The representative set of structures analysed in $[50,51]$ includes structures of different constitutive materials. However, to keep the comparison consistent, only the results corresponding to RC structures are evaluated here. The representative 
set of RC structures analysed in $[50,51]$ is constituted by 2256 different nominal building configurations.

The number of relevant hazard scenarios $n_{j}$ associated with structures, where in addition to the persistent situations accidental load arrangements must be considered, is comparatively higher. Due to this reason, the implicitly acceptable risks found here are larger compared to those obtained in [50, 51], shown in Fig.8b as square-shaped dots. The herein obtained mean value $\left(\mathrm{R} / \mathrm{n}_{\mathrm{k}}\right)_{\text {TOT,m }}$ is about 2.2 times higher than $\left(\mathrm{R} / \mathrm{n}_{\mathrm{k}}\right)_{\mathrm{PER}, \mathrm{m}}$ deduced in [50, 51]. Interestingly, even when normalising risks $\mathrm{R}$ for the number of hazard scenarios $\left(\mathrm{n}_{\mathrm{j}}\right)$, this difference cannot be entirely eliminated $\left(\left(\mathrm{R} / \mathrm{n}_{\mathrm{j}}\right)_{\text {TOT,m }} /\left(\mathrm{R} / \mathrm{n}_{\mathrm{j}}\right)_{\mathrm{PER}, \mathrm{m}} \approx 1.6\right)$. The comparatively high member failure probabilities associated with the highly uncertain explosion load (Section 4.4) reasonably explain this circumstance.

\subsection{Development of safety requirements}

\subsubsection{Total failure probability}

In view of applications in routine practice, a performance criterion in terms of structural member failure probabilities is established (Eq. 9). This criterion limits the total failure probability $\mathrm{p}_{\mathrm{f}, \mathrm{TOT}}$, stemming from the sum of the relevant persistent- and accidental hazard scenarios, $\mathrm{p}_{\mathrm{f}, \mathrm{PER}}$ and $\mathrm{p}_{\mathrm{f}, \mathrm{EX}}$, respectively, to a target value $\mathrm{p}_{\mathrm{ft}, \mathrm{TOT}}$.

$\mathrm{p}_{\mathrm{f}, \mathrm{TOT}}=\mathrm{p}_{\mathrm{f}, \mathrm{PER}}+\mathrm{p}_{\mathrm{f}, \mathrm{EX}} \leq \mathrm{p}_{\mathrm{ft}, \mathrm{TOT}}$

Frequency-consequence curves (F-N curves) are used to derive target probabilities $\mathrm{p}_{\mathrm{ft}, \mathrm{TOT}}$. They show the frequency $F$ of events with $n \geq N$ fatalities $[11,55]$, where $F(1)$ and $\alpha$ are constants:

$\mathrm{F}(\mathrm{n})=\mathrm{p}(\mathrm{n} \geq \mathrm{N}) \leq \mathrm{F}(1) \cdot \mathrm{n}^{-\alpha}$

An exponent $\alpha$ greater than 1 accounts for social aversion to events implying larger consequences. Usually employed values are $\alpha=1$ to 2 [55]. The constant $F(1)$ represents the frequency of occurrence of an event with $\mathrm{n} \geq 1$ fatalities. As a general rule, its value should be consistent with the reference system to which the F-N criterion is applied [51]. In [26], F-N based acceptance criteria for entire structures have been developed, where the size of the reference system is represented by the building net room area. In the present case, the reference system corresponds to a particular structural member, whose failure might be potentially triggered by both persistent and accidental load arrangements. For this case, constant $\mathrm{F}(1)$ is derived as described in the following.

Fig. $8 \mathrm{~b}$ shows the admissible structure-related risks normalized for the number of failure modes, $\left(\mathrm{R} / \mathrm{n}_{\mathrm{k}}\right)_{\text {тот, }}$ where $\mathrm{R}$ represents the expected number of fatalities associated with a particular structure in a 50-year reference period. In turn, the expected number of fatalities associated with a specific system, $\mathrm{E}(\mathrm{N})$, can be conservatively represented by the area under the respective F-N curve. This area can be calculated approximately with Eq. (11) if $\alpha>1$.

$$
\mathrm{E}(\mathrm{N})=\int \mathrm{F}(\mathrm{n}) \mathrm{dn} \approx \mathrm{F}(1) \cdot \frac{\alpha}{\alpha-1} \quad[\alpha>1]
$$

Hence, when substituting $\left(\mathrm{R} / \mathrm{n}_{\mathrm{k}}\right)_{\text {Tот }}$ for $\mathrm{E}(\mathrm{N})$ in Eq. (11), the 50 year target cumulative frequency of occurrence for a collapse event of a structural member with $\mathrm{n} \geq 1$ fatalities, $\mathrm{F}(1) \mathrm{t}, \mathrm{TOT}$, can be deduced. The risk aversion exponent is assumed as $\alpha=2$ in order to assure consistency with [51]. Given $\mathrm{F}(1)_{\mathrm{t}, \mathrm{TOT}}$ and $\alpha$, the target frequencies $\mathrm{F}(\mathrm{n})_{\mathrm{t}, \mathrm{TOT}}$ are defined as 
per Eq. (10). This procedure avoids possible inconsistencies regarding the expected number of fatalities $\mathrm{E}(\mathrm{N})$ associated with the system and consequently contributes to rational decision-making [36].

The deduced target frequencies $\mathrm{F}(\mathrm{n})_{\mathrm{t} \text {,тОт }}$ are subsequently converted to target probabilities $\mathrm{p}_{\mathrm{ft}, \mathrm{TOT}}$ with Eq. (12). In this equation, $\mathrm{p}_{\mathrm{N} \mid \mathrm{f}}$ describes the conditional probability of $\mathrm{n} \geq \mathrm{N}$ fatalities in the event of failure. For want of more specific data and as a conservative approximation, $\mathrm{p}_{\mathrm{N} \mid \mathrm{f}}$ is replaced by the conditional probability of death of a person given the collapse. In [46] a value of 0.05 is suggested for this probability, which is adopted in the present study. In future studies, the assumption for $\mathrm{p}_{\mathrm{N} \mid \mathrm{f}}$ should be improved.

$\mathrm{F}(\mathrm{n})_{\mathrm{t}, \mathrm{TOT}} \cong \mathrm{p}_{\mathrm{ft}, \mathrm{TOT}} \cdot \mathrm{p}_{\mathrm{N} \mid \mathrm{f}}$

The obtained $\mathrm{p}_{\mathrm{ft}, \text { TOT }}$ are reflected in Fig. 9a (based on mean value $\left.\left(\mathrm{R} / \mathrm{n}_{\mathrm{k}}\right)_{\mathrm{TOT}, \mathrm{m}}\right)$ and Fig. $9 \mathrm{~b}$

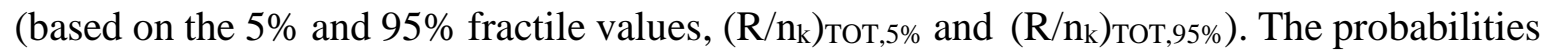
$\mathrm{p}_{\mathrm{ft}, \mathrm{TOT}}$ are plotted versus the area affected by the member collapse $\left(\mathrm{A}_{\mathrm{col}}\right)$, converted from the number of fatalities $(\mathrm{N})$ under use of the consequence model (Eq. 8) employed to derive the implicitly acceptable risks. Reasonably, $\mathrm{p}_{\mathrm{ft}, \text { Тот }}$ decreases with increasing potential structural damage a member collapse might induce. It is further shown that the deduced $\mathrm{p}_{\mathrm{ft}, \mathrm{TOT}}$ exceed the corresponding target values for persistent situations $\mathrm{p}_{\mathrm{ft}, \mathrm{PER}}[50,51]$ in about 2-3 times, what is attributable to the comparatively higher acceptable risks (Fig. 8b).

In addition to this plausible finding, economical criteria, although not specifically addressed in the present study, deliver arguments to establish less demanding safety requirements for potentially explosion-exposed structural members. Keeping in mind that higher safety levels might involve prohibitive costs in case of large uncertainties [35], lower requirements would seem to be defendable in case the reliability level associated with a specific member failure mode is dominated by the highly uncertain, explosion-induced loads. However, the member reliability analysis carried out in the present study showed that there are multiple situations in practice where this is not the case. Often, the contribution of the persistent building use conditions $\mathrm{p}_{\mathrm{f}, \mathrm{PER}}$ to the total failure probability $\mathrm{p}_{\mathrm{f}, \mathrm{TOT}}$ (Eq. 9) of a potentially explosion-exposed member is significant, in many cases even totally dominant. This suggests that the safety requirements for potentially explosion-exposed members should ideally be a function of the degree of influence of the persistent load arrangements on the member reliability. As a rule, the lower this influence the less demanding should be the target value.

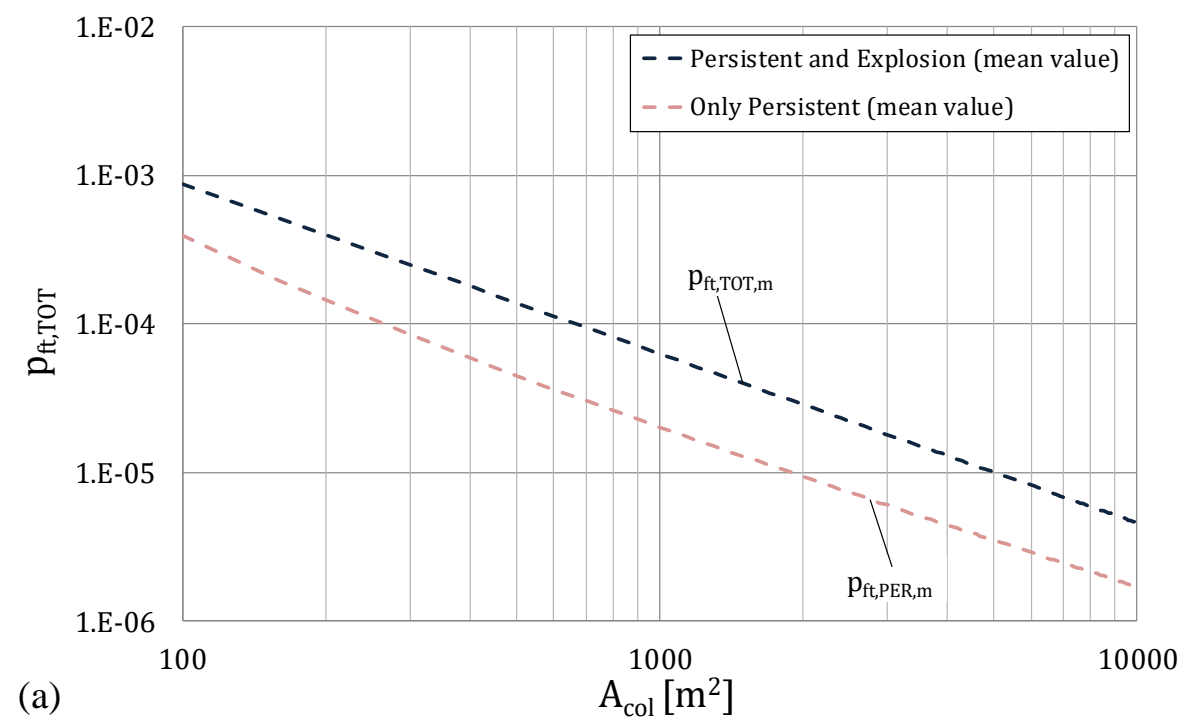




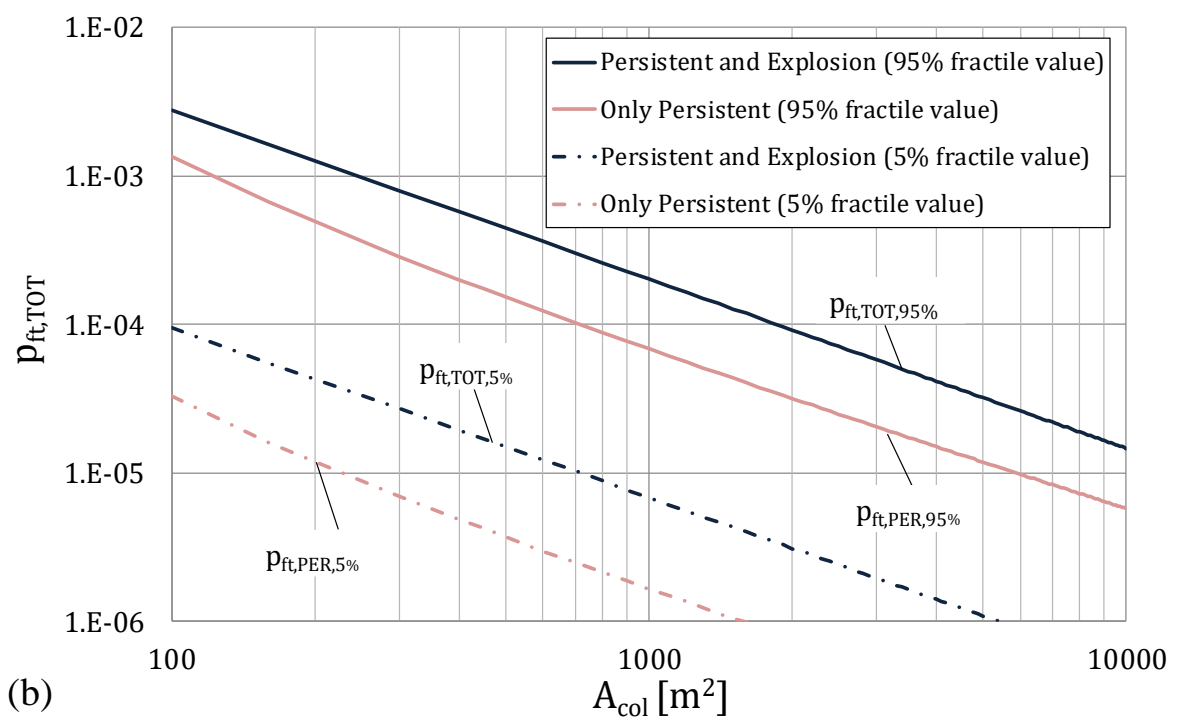

Fig. 9. Target failure probabilities $\mathrm{p}_{\mathrm{ft}, \mathrm{TO}}$ based on the mean value (a) and the $5 \%$ or $95 \%$ fractile values (b) of implicitly acceptable, normalised risks $\left(\mathrm{R} / \mathrm{n}_{\mathrm{k}}\right)_{\text {TOT }}$; Comparison to results from prior studies, $\mathrm{p}_{\mathrm{ft}, \mathrm{PER}} ; \mathrm{T}_{\mathrm{ref}}=50$ years.

\subsubsection{Conditional failure probability}

Based on the arguments put forward in the previous section, a target value $\mathrm{p}_{\mathrm{ft} t \mathrm{EX}}$ for the conditional member failure probability due to the accidental load arrangement, $\mathrm{p}_{\mathrm{f} \mid \mathrm{EX}}$ (given that a gas explosion occurs and the member in question is exposed to the generated pressure wave), is defined. The starting point is the general performance criterion given by Eq. (9). Under consideration of the occurrence probability of an explosion event p(EX), Eq. (9) can be translated into the following requirement:

$\mathrm{p}_{\mathrm{f} \mid \mathrm{EX}} \leq \mathrm{p}_{\mathrm{ft} \mid \mathrm{EX}}=\frac{\mathrm{p}_{\mathrm{ft}, \mathrm{TOT}}-\mathrm{p}_{\mathrm{f}, \mathrm{PER}}}{\mathrm{p}(\mathrm{EX})}$

According to Eq. (13), the conditional target failure probability pft|Ex for a potentially explosion-exposed member decreases with rising contribution of the persistent load arrangements $\mathrm{p}_{\mathrm{f}, \mathrm{PER}}$ to the total member failure probability. This is in line with the general idea outlined above. The target values for the total failure probability, pft,TOT, are given in Fig. 9 as a function of $\mathrm{A}_{\text {col }}$. Factoring the corresponding equations into Eq. (13), along with $\mathrm{p}(\mathrm{EX}) \approx \lambda \cdot \mathrm{T}_{\text {ref }}$ $=5 \cdot 10^{-4}$ (Section 4.4), the conditional target probability $\mathrm{p}_{\mathrm{ft} \mid \mathrm{EX}}$ is defined by Eq. (14) as a function of constant $\mathrm{C}_{1}$ and probability $\mathrm{p}_{\mathrm{f}, \mathrm{PER}}\left(\mathrm{T}_{\mathrm{ref}}=50\right.$ years $)$.

$\mathrm{p}_{\mathrm{ft} \mid \mathrm{EX}}=\mathrm{C}_{1} \cdot \mathrm{A}_{\mathrm{col}}{ }^{-1.14}-2 \cdot 10^{3} \cdot \mathrm{p}_{\mathrm{f}, \mathrm{PER}} \leq 1$

where:

$\mathrm{C}_{1 ; 5 \%}=36$ (5\% fractile value); $\mathrm{C}_{1 ; \mathrm{m}}=331$ (mean value); $\mathrm{C}_{1 ; 95 \%}=1061$ (95\% fractile value)

The maximum value for $\mathrm{p}_{\mathrm{ft} \mid \mathrm{EX}, \max }$ corresponds to situations where the contribution of the persistent load arrangements is not relevant $\left(\mathrm{p}_{\mathrm{f}, \mathrm{PER}} \approx 0\right)$, hence:

$\mathrm{p}_{\mathrm{ft} \mid \mathrm{EX}, \max }=\mathrm{C}_{1} \cdot \mathrm{A}_{\mathrm{col}}^{-1.14} \leq 1$

A minimum value $\mathrm{p}_{\mathrm{ft} \mid \mathrm{EX}, \min }$ can be defined by limiting probability $\mathrm{p}_{\mathrm{f}, \mathrm{PER}}$ in any case to a target value $\mathrm{p}_{\mathrm{ft}, \mathrm{PER}}$. Thereby consistency to the prior studies $[50,51]$ is assured. When factoring the equations for the $\mathrm{p}_{\mathrm{ft}, \mathrm{PER}}$ criteria shown in Fig. 9 into Eq. (14) and simplifying the result, the following approximate formulation is obtained for $\mathrm{p}_{\mathrm{ft} \mid \mathrm{EX}, \mathrm{min} \text { : }}$ 
$\mathrm{p}_{\mathrm{ft} \mid \mathrm{EX}, \min }=\mathrm{C}_{2} \cdot \mathrm{A}_{\mathrm{col}}^{-1.11} \leq 1$

where:

$\mathrm{C}_{2 ; 5 \%}=20$ (5\% fractile value); $\mathrm{C}_{2 ; \mathrm{m}}=167$ (mean value); $\mathrm{C}_{2 ; 95 \%}=565$ (95\% fractile value)

Fig. 10a plots the minimum target value $\mathrm{p}_{\mathrm{ft}} \mathrm{EX}$,min according to Eq. (16). The results based on, respectively, the 5\% fractile-, the mean- and the $95 \%$ fractile value of the implicitly accepted risks are shown. The most restrictive criterion (5\% fractile) applies for members whose collapse would affect an area of at least $\mathrm{A}_{\mathrm{col}, \text { min }} \approx 15 \mathrm{~m}^{2}$ (areas below $\mathrm{A}_{\text {col,min }}$ deliver $\mathrm{p}_{\mathrm{ft} t \mathrm{EX} \text {,min }}>$ $1)$. When the mean value criterion is referred to, $A_{\text {col,min }}$ increases to $100 \mathrm{~m}^{2}$, whereas the result based on the $95 \%$ fractile is not valid below $A_{\text {col,min }} \approx 300 \mathrm{~m}^{2}$. The $A_{\text {col,min }}$ thresholds

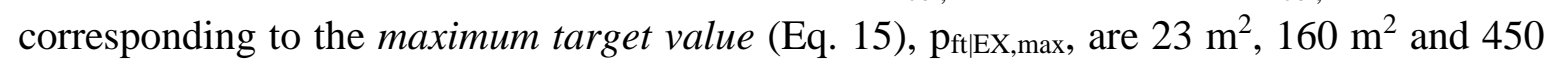
$\mathrm{m}^{2}$, respectively (Fig. 10b). Interestingly, the obtained $\mathrm{A}_{\text {col,min }}$ values based on the mean value of the implicitly acceptable risks, of $100 \mathrm{~m}^{2}$ and $160 \mathrm{~m}^{2}$, are of the same order as the threshold areas suggested in EN 1991-1-7 [20] for limiting the extent of localized failure due to an unspecified cause. The mentioned standard considers an area of $\mathrm{A}_{\mathrm{col}}=100 \mathrm{~m}^{2}$ or $15 \%$ of the floor area, whichever is less, on two adjacent floors caused by the removal of any member, as acceptable and likely to provide the structure with sufficient robustness. This observation supports the plausibility of the herein obtained criteria for rational decisionmaking concerning structural safety related to accidental situations.

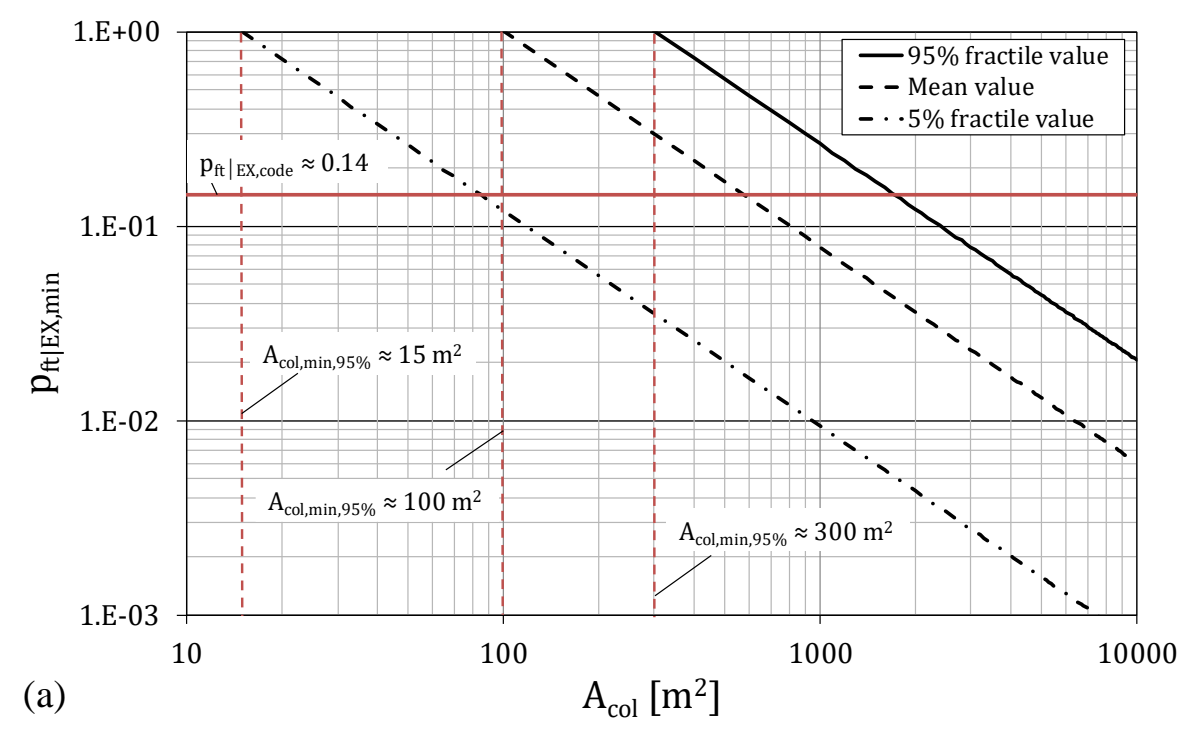




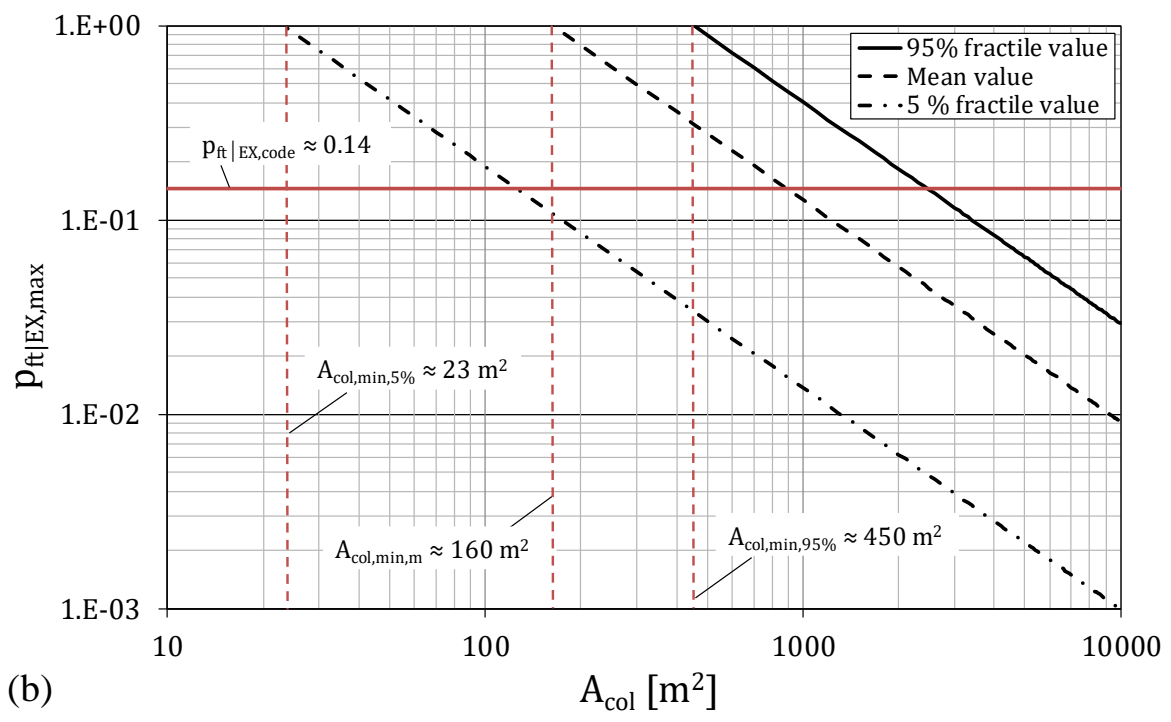

Fig. 10. Minimum (a) and maximum (b) target value for conditional failure probabilities, $\mathrm{p}_{\mathrm{ft|EX}}\left(\mathrm{T}_{\mathrm{ref}}\right.$ $=50$ years for concomitant gravitational loads)

In case the potential member collapse would affect an area larger than the established $\mathrm{A}_{\text {col,min, }}$, verification of structural reliability associated with the accidental situation would be required. The diminishing target failure probabilities $\mathrm{p}_{\mathrm{ft} \mid \mathrm{EX}}$ with increasing $\mathrm{A}_{\mathrm{col}}$ (Fig. 10) account for aversion to collapse events with large consequences. In this regard, they constitute a powerful tool for the design or the assessment of key elements, upon which, according to the definition in EN 1991-1-7 [20], the stability of (the remainder of) the structure depends. However, besides from the above-mentioned limit for admissible local failure due to an unspecified cause, no distinctions are made in EN 1991-1-7 [20] regarding acceptable failure consequences, nor is the required reliability level associated with the design of such elements explicitly established. The implicit, nominal target ceiling demanded in the Eurocode [18] can be inferred from Eq. (17) under consideration of the 50 year target reliability index $\beta_{\mathrm{t} \text {,code }}=3.8(\phi=$ standard normal distribution) and the herein considered explosion occurrence probability during this reference period, $\mathrm{p}(\mathrm{EX})=5 \cdot 10^{-4}$. The result, $\mathrm{p}_{\mathrm{ft} \mid \mathrm{EX} \text {,code }} \approx 0.14$, is compared in Fig. 10 to the herein derived $\mathrm{p}_{\mathrm{ft} \mid \mathrm{EX}}$ - criteria. It can be observed that for relatively small areas $A_{c o l}$, the Eurocode requirement is stricter then the herein proposed target values based on the intrinsically accepted risks. On the contrary, if the collapse of a structural member entails a very large $A_{\text {col }}$, the herein deduced acceptance criteria imply lower target failure probabilities than the current Eurocode requirement.

$\mathrm{p}_{\mathrm{ft} \mid \mathrm{EX}, \text { code }}=\frac{\phi\left(-\beta_{\mathrm{t}, \text { code }}\right)}{\mathrm{p}(\mathrm{EX})}=\frac{7.2 \cdot 10^{-5}}{5 \cdot 10^{-4}} \approx 0.14$

\subsubsection{Recommendations}

Keeping in mind the arguments considered for derivation of the conditional target probabilities $p_{\mathrm{ft} \mid \mathrm{EX}}$, the maximum values $\mathrm{p}_{\mathrm{ft} \mid \mathrm{EX} \text {,max }}$ (Fig. 10b) could be established as an acceptance criterion in case it could be assured that the explosion loads are dominant for a certain structural failure type. For instance, this is the case for failure modes only scantly affected by persistent load arrangements. On the contrary, when a significant contribution of the persistent situations to the failure probability could not be precluded, the target failure probabilities should be reduced according to Eq. (14) as a function of probability $\mathrm{p}_{\mathrm{f}, \mathrm{PER}}$. For sake of simplicity, and since it is a conservative approach, the minimum target values $\mathrm{p}_{\mathrm{ft} t \mathrm{EX}, \min }$ (Fig. 10a) 
could be of general application for verification of structural safety in relation with explosionexposure.

In comparison to the rather small differences between the $\mathrm{p}_{\mathrm{ft} \mid \mathrm{EX}, \min }$ and $\mathrm{p}_{\mathrm{ft} \mid \mathrm{EX}, \max }$ criterion (Fig. 10), the discrepancies between the 5\%, the mean and the $95 \%$ fractile values for $\mathrm{p}_{\mathrm{ft} \mid \mathrm{EX}}$ are substantial (more than one order of magnitude). A criteria for the selection of an appropriate fractile value could be the annual fatality rate of the building users [23, 34]. In the framework of the present study, a consistent relationship between the implicitly acceptable fatality rate and the risks R (Eq. 1), normalised for the building net-room area A, can be established [26, $50,51]$. It is found that for the herein analysed $\mathrm{RC}$ structures, this rate oscillates between $5 \cdot 10^{-6} \mathrm{y}^{-1}$ (corresponding to the $5 \%$ fractile value of $\mathrm{R}$ ) and $5 \cdot 10^{-5} \mathrm{y}^{-1}$ (corresponding to the $95 \%$ fractile value of R). Based on the general consensus on acceptable levels for new and existing facilities $[25,44,46,47,49,54]$, of $10^{-6} \mathrm{y}^{-1}$ and $10^{-5} \mathrm{y}^{-1}$, respectively, the adoption of the $95 \%$ fractile value of $\mathrm{p}_{\mathrm{ft} \mid \mathrm{EX}}$ would seem to be generally too permissive. Rather, it might be reasonable to adopt the 5\% fractile criteria for purpose of a design criteria. The mean value of $p_{\mathrm{ft} \mid \mathrm{EX}}$, associated with an implicitly acceptable annual fatality rate of about $2 \cdot 10^{-5} \mathrm{y}^{-}$ 1 , could be envisaged for assessment of existing elements.

\section{Conclusions}

The present contribution explores practical methods and tools for the analysis and evaluation of structure-related life safety risks associated with the effects of gas explosions on reinforced concrete structures for residential buildings. The developments include models for the estimation of both the occurrence probabilities and the consequences of explosion-induced structural collapse. A representative set of RC building structures designed in accordance with current best practice is analyzed under consideration of a potential explosion exposure. It is found that the associated implicitly acceptable risks are higher than those obtained for structures under normal use conditions (persistent situations), analysed in prior studies. This is attributable to a comparatively higher number of potential hazard scenarios and to the high uncertainties associated with the explosion load. Under consideration of these findings, frequency-consequence curves are then used to obtain reliability requirements in terms of the total target failure probability for potentially explosion-exposed structural mem-

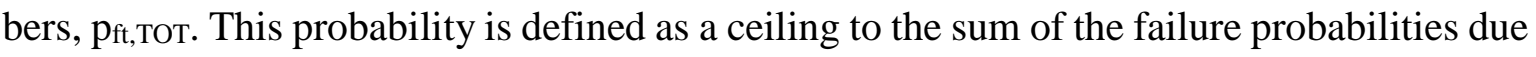
to the relevant explosion and persistent load arrangements for the member under consideration, respectively, $\mathrm{p}_{\mathrm{f}, \mathrm{EX}}$ and $\mathrm{p}_{\mathrm{f}, \mathrm{PER} \text {. }}$

Taking into account the results for $\mathrm{p}_{\mathrm{ft}, \mathrm{TOT}}$ and the occurrence probability of a gas explosion in residential buildings, target values for the conditional failure probability $\mathrm{p}_{\mathrm{ft} \mid \mathrm{Ex}}$ of a structural member, given such an event, are subsequently derived. The $\mathrm{p}_{\mathrm{ft}} \mathrm{EX}$ are defined as a function of the area affected by the collapse of a particular structural member $\left(\mathrm{A}_{\mathrm{col}}\right)$. Minimum areas $A_{c o l, m i n}$ are obtained below which a specific design solution would be acceptable without need for any intervention regarding explosion-related structural reliability. For such cases member design could be based on the persistent situation under consideration of normal load conditions only, without any further provisions for this accidental situation. As far as the results based on the mean value of the implicitly acceptable risks are concerned, $\mathrm{A}_{\mathrm{col}, \text { min }}$ oscillates around $100-160 \mathrm{~m}^{2}$. Beyond these threshold areas, diminishing $\mathrm{p}_{\mathrm{ft} \mid \mathrm{EX}}$ with increasing $\mathrm{A}_{\mathrm{col}}$ account for aversion to collapse events with larger consequences to personal 
integrity. The deduced criteria facilitate the adoption of rational decisions on both, the need and the appropriate choice of risk-reduction measures to counteract the effects of gas explosions on building structures.

\section{Acknowledgements}

The first author wishes to thank Dr. Dimitris Diamantidis and Dr. Dirk Proske for their contribution as external reviewers of the $\mathrm{PhD}$ thesis [26] on which the present paper is based.

\section{References}

[1] ABC. 132 muertos en explosiones de gas en la última década. 2010.

[2] Bach A, Stolz A, Nöldgen M, Thoma K. Zuverlässigkeit innerhalb der Auslegung von Stahlbetonplatten unter Explosionsbelastung nach Eurocode. Beton- und Stahlbetonbau. 2013;108:528-39.

[3] Bela G. Design of Buildings to Withstand Abnormal Loading: Butterworths; 1990.

[4] Beshara FBA. Modelling of blast loading on aboveground structures-II. Internal blast and ground shock. Computers and Structures. 1994;51:597-606.

[5] Biggs JM. Introduction to Structural Dynamics: McGraw-Hill; 1964.

[6] Burnett EFP. Abnormal Loading and Building Safety. American Concrete Institute (ACI): Special Publication. 1975;48:141-90.

[7] CEB-FIP. Model Code 1990. London: Comité Euro-International du Béton; 1993.

[8] Corres Peiretti H, Romero Rey E. Reconstrucción "Módulo D" Aparcamiento Madrid Barajas T-4. IV Congreso de ACHE (Asociación Científico-Técnica del Hormigón Estructural). Valencia; 2008.

[9] CTE. Código Técnico de la Edificación: Documento Básico SE-AE, Acciones en la edificación (Borrador). Madrid; 2003.

[10] CTE. Código Técnico de la Edificación: Documento Básico SE, Seguridad Estructural (Borrador). Madrid; 2003.

[11] Diamantidis D, Vrouwenvelder T. Chapter 9: Acceptance criteria. In: Diamantidis D, Holický M, editors. Innovative methods for the assessment of existing structures; 2012. p. 110-21.

[12] Dragosavic M. Structural measures against natural-gas explosions in highrise blocks of flats. Heron. 1973;19.

[13] EHE-98. Instrucción de Hormigón Estructural, Ministerio de Fomento. Madrid; 2000.

[14] El Mundo. Las explosiones de gas más graves de la década. 2007.

[15] Ellingwood BR. Mitigating Risk from Abnormal Loads and Progressive Collapse. Journal of Performance of Constructed Facilities. 2006;20:315-23.

[16] Ellingwood BR, Dusenberry DO. Building Design for Abnormal Loads and Progressive Collapse. Computer-Aided Civil and Infrastructure Engineering. 2005;20:12.

[17] Ellis BR, Currie DM. Gas explosions in buildings in the UK: Regulation and risk. Structural Engineer. 1998;76:373-80.

[18] EN 1990. Eurocode - Basis of structural design. Brussels: European Committee for Standardization; 2002.

[19] EN 1991-1-1. Eurocode. Actions on structures. General actions - Densities, selfweight, imposed loads for buildings. Brussels: European Committee for Standardization; 2002.

[20] EN 1991-1-7. Eurocode 1: Actions on structures - Part 1.7: General actions - Accidental Actions. Brussels: European Committee for Standardization; 2006. 
[21] EN 1992-1-1. Eurocode 2: Design of concrete structures - Part 1-1: General rules and rules for buildings. Brussels: European Committee for Standardization; 2004.

[22] Faber MH. Risk and Safety in Civil Engineering. Lecture Notes, Eidgenössische Technische Hochschule Zürich; 2007.

[23] Faber MH, Sørensen JD, Vrouwenvelder A. On the regulation of Life Safety Risk. 12th International Conference on Applications of Statistics and Probability in Civil Engineering (ICASP 12). Vancouver; 2015.

[24] fib. Model Code for Concrete Structures 2010. Fédération internationale du béton; 2013. [25] fib. Bulletin 80, Partial Factor Methods for Existing Concrete Structures: Fédération internationale du béton; 2016.

[26] Hingorani R. Acceptable life safety risks associated with the effects of gas explosions on reinforced concrete structures: Universidad Politécnica de Madrid (UPM). https://doi.org/10.20868/UPM.thesis.47772; 2017.

[27] Hingorani R, Tanner P. Application of risk analysis in structural engineering - Gas explosions. 4th International RILEM PhD Workshop. 2010.

[28] Hingorani R, Tanner P. Nivel de fiabilidad implícito de pilares de hormigón armado sometidos a la interacción de esfuerzos axiles y momentos flectores. V Congreso de ACHE. Barcelona; 2011.

[29] Hingorani R, Tanner P, Hendriks MAN. Validation of simplified models for the analysis of reinforced concrete beams exposed to gas explosions. Engineering for Progress, Nature and People; 2014. p. 293-300.

[30] Hingorani R, Tanner P, Zanuy C. Reliability of RC members submitted to gas explosions. IABSE Congress Stockholm, 2016: Challenges in Design and Construction of an Innovative and Sustainable Built Environment; 2016. p. 447-55.

[31] Holand I. Design philosophy for accidental actions. IABSE Reports. 1996;74:7.

[32] IBM. SPSS Statistics for Windows. IBM Corp, Armonk, NY; 2012.

[33] INE. Instituto Nacional de Estadística.

[34] ISO 2394: 2015. General principles on reliability for structures, 4th edition. International Organization for Standardization (ISO); 2015.

[35] JCSS. Probabilistic Model Code, Part 1 - Basis of design. Joint Committee on Structural Safety 2000.

[36] Kroon IB, Maes MA. Background Documents on Risk Assessment in Engineering. Document 1: Theoretical Framework for Risk Assessment and Evaluation. Joint Committee of Structural Safety (JCSS); 2008.

[37] Leyendecker EV, Ellingwood BR. Design methods for reducing the risk of progressive collapse in buildings. NBS Building Science Series. 1977;98.

[38] Magnusson J. Structural concrete elements subjected to air blast loading TRITA-BKN. Bulletin 92: Royal Institute of Technology, Stockholm; 2007.

[39] Malvar LJ, Crawford JE. Dynamic Increase Factors for Steel Reinforcing Bars. Twenty-Eighth DDESB Seminar Orlando, FL; 1998.

[40] Mihashi H, Wittmann FH. Stochastic approach to study the influence of rate of loading on the strength of concrete. Heron. 1980;25:1-54.

[41] Oswald C, Bazan M. Comparison of SDOF analysis results to test data for different types of blast loaded components. Structures Congress 2014 - Proceedings; 2014. p. 11730.

[42] PEC - Petschacher Consulting ZT-GmbH. Variables Processor (VaP). 3.5 ed: http://www.petschacher.at/en/software-it/; 2016.

[43] Schmidt H. Versagenswahrscheinlichkeit unbewehrter Wand-Decken-Verbindungen bei Gasexplosionen im Fertigteilbau: Technische Universität Darmstadt; 2003.

[44] SIA 269. Grundlagen zur Erhaltung von Tragwerken. Zürich: Schweizerischer Ingenieur- und Architektenverein; 2011. 
[45] Starossek U. Interaktion und progressiver Kollaps, Report, 9. Dresdner BaustatikSeminar. In: Möller B, editor.: TU Dresden; 2005.

[46] Steenbergen RDJM, Sykora M, Holicky M, Diamantidis D, Vrouwenvelder ACWM. Economic and human safety reliability levels for existing structures Structural Concrete. 2015; 16:323-32.

[47] Steenbergen RDJM, Vrouwenvelder ACWM. Safety philosophy for existing structures and partial factors for traffic loads on bridges. Heron. 2010;55:123-40.

[48] Stewart MG. Reliability-based load factor design model for explosive blast loading. Structural Safety. 2018;71:13-23.

[49] Sykora M, Diamantidis D, Holicky M, Jung K. Target reliability for existing structures considering economic and societal aspects. Structure and Infrastructure Engineering. 2017; 13:181-94.

[50] Tanner P, Hingorani R. Development of risk-based requirements for structural safety. Joint IABSE - fib Conference: Codes in Structural Engineering - Developments and Needs for International Practice. Dubrovnik; 2010.

[51] Tanner P, Hingorani R. Acceptable risks to persons associated with building structures. Structural Concrete. 2015;16:314-22.

[52] Tanner P, Lara C, Hingorani R. Seguridad estructural. Una lucha con incertidumbres. Hormigón y Acero. 2007;245:59-78.

[53] Technical Manual TM5-1300. Design of structures to resist the effects of accidental explosions. US Department of the Army; 1990.

[54] Vrijling JK, Van Gelder PHAJM, Ouwerkerk SJ. Criteria for acceptable risk in the Netherlands In: Taylor C, Van Marcke E, editors. Infrastructure Risk Management Processes: Natural, Accidental, and Deliberate Hazards: American Society of Civil Engineers (ASCE); 2005. p. 143-58.

[55] Vrouwenvelder A, Lovegrove R, Holicky M, Tanner P, Canisius G. Risk Assessment and Risk Communication in Civil Engineering. Rotterdam: International Council for Research and Innovation in Building and Construction; 2001.

[56] Vrouwenvelder T. Stochastic modelling of extreme action events in structural engineering. Probabilistic Engineering Mechanics. 2000;15:109-17.

[57] Vrouwenvelder T. Chapter V - Accidental Actions on Buildings. In: CZ/02/B/F/PP134007 LDVPP, editor. Implementation of Eurocodes Handbook 3: Design of buidlings Guide to basis of structural reliability and risk engineering related to Eurocodes supplemented by practical examples; 2005.

[58] Vrouwenvelder T, Leira B. Probabilistic modelling of internal gas explosions. Joint Workshop of COST Actions TU0601 and E55. Ljubljana, Slowenia; 2009.

[59] Vrouwenvelder T, Leira BJ, Sykora M. Modelling of Hazards. Structural Engineering International 2012;22:73-8.

[60] Wees V, R. M. M., Peters DJ. Accuracy and range of applicability of the single-degreeof-freedom method. Seventh International Symposium on Interaction of the Effects of Munitions with Structures. Mannheim; 1995. p. 371-80.

[61] Zeeuwen JP, Van Wingerden CJM. Pressure loads on control rooms resulting form gas explosions. Internationales Kolloquium für die Verhütung von Arbeitsunfällen und Berufskrankheiten in der chemischen Industrie. Frankfurt am Main; 1985. 